\title{
Common brain activations for painful and non-painful aversive stimuli
}

\author{
Dave J Hayes ${ }^{*}$ and Georg Northoff
}

\begin{abstract}
Background: Identification of potentially harmful stimuli is necessary for the well-being and self-preservation of all organisms. However, the neural substrates involved in the processing of aversive stimuli are not well understood. For instance, painful and non-painful aversive stimuli are largely thought to activate different neural networks. However, it is presently unclear whether there is a common aversion-related network of brain regions responsible for the basic processing of aversive stimuli. To help clarify this issue, this report used a cross-species translational approach in humans (i.e. meta-analysis) and rodents (i.e. systematic review of functional neuroanatomy).

Results: Animal and human data combined to show a core aversion-related network, consisting of similar cortical (i.e. MCC, PCC, Al, DMPFC, RTG, SMA, VLOFC; see results section or abbreviation section for full names) and subcortical (i.e. Amyg, BNST, DS, Hab, Hipp/Parahipp, Hyp, NAc, NTS, PAG, PBN, raphe, septal nuclei, Thal, LC, midbrain) regions. In addition, a number of regions appeared to be more involved in pain-related (e.g. sensory cortex) or non-pain-related (e.g. amygdala) aversive processing.

Conclusions: This investigation suggests that aversive processing, at the most basic level, relies on similar neural substrates, and that differential responses may be due, in part, to the recruitment of additional structures as well as the spatio-temporal dynamic activity of the network. This network perspective may provide a clearer understanding of why components of this circuit appear dysfunctional in some psychiatric and pain-related disorders.
\end{abstract}

Keywords: Meta-analysis, Translational, Aversion, Pain, Neuroimaging, Animal models

\section{Background}

Aversion: painful and non-painful stimuli

Identification of potentially harmful stimuli is necessary for the well-being and self-preservation of all organisms. Organisms with relatively simple nervous systems (e.g. worms, fruit flies) display motivated approach and avoidance behaviours to rewarding and aversive stimuli, respectively, implying the existence of some evolutionarily conserved mechanisms [1,2]. Aversive stimuli are those which an organism will generally expend energy to minimize or avoid [3]; in this context, aversion is operationally opposite to reward [4]. However, the strength of aversive stimuli and the context in which they occur can produce a variety of psychophysical (e.g. negative emotion, pain) and behavioural (e.g. reduced behaviour following punishment, avoidance) responses. While

\footnotetext{
* Correspondence: david.hayes@theroyal.ca

Mind, Brain Imaging and Neuroethics Research Unit, Institute of Mental

Health Research, University of Ottawa, 1145 Carling Avenue, Ottawa K1Z 7K4,
} Canada

\section{Biomed Central

(c) 2012 Hayes and Northoff; licensee BioMed Central Ltd. This is an Open Access article distributed under the terms of the Creative Commons Attribution License (http://creativecommons.org/licenses/by/2.0), which permits unrestricted use, distribution, and reproduction in any medium, provided the original work is properly cited. recent work has suggested the existence of a common aversion-related network of brain regions responsible for the basic processing of aversive stimuli [5], this work focused only on studies involving non-painful stimuli and studies including painful stimuli were not considered; as such, it is unclear if those results extend to pain-related processing.

\section{Pain-associated brain activity}

Pain, which typically results from activating the nociceptive system (but can also involve non-nociceptive mechanisms, such as in neuropathic pain), is experienced across mammals and is critical for survival [6]. Studies in humans and non-human animals have generally supported the notion that pain is processed differentially in the brain according to affective (e.g. amygdala, anterior insula, hippocampus) and sensory (e.g. somatosensory cortices, posterior insula) dimensions (e.g. [7-9]; though see also [10] for a review on the influential 3dimension theory of pain). Nonetheless, the assumption 
that this network (sometimes referred to as the 'Pain Matrix') is specifically activated by painful stimuli has been questioned [11-13]. Using fMRI in humans, Mouraux et al. (2011) uncovered strong support for the notion that the typical regions of the Pain Matrix are largely involved in salience processing [12]. They showed that multimodal non-painful aversive stimuli and painful stimuli activate similar regions in the MCC, insula, thalamus, and sensory cortex and that the BOLD signals in these regions correlated largely with the perceived saliency of the stimulus (regardless of modality or stimulus type).

\section{Studies suggest shared regions for pain and non-pain aversion}

While much work has identified pain as a uniquely important experience (e.g. [10,14]), numerous studies using non-painful aversive stimuli (e.g. unpleasant sounds, sights, etc.) have implicated many of the same cortical and subcortical regions [5], suggesting that the processing of various painful and non-painful aversive stimuli require many of the same neurobiological substrates. In this regard, human studies have been key to understanding the role of cortical regions (e.g. prefrontal and insular cortices; e.g. $[15,16])$. Alternately, studies in animals have highlighted the importance of subcortical areas such as the periaqueductal grey, hypothalamus, bed nucleus of the stria terminalis, nucleus accumbens/ ventral striatum and ventral tegmental area [17-20]. While prior work has identified a network of regions involved in non-painful aversion-related processing [5], it nonetheless remains unclear which, if any, of those identified areas are also involved in processing painful stimuli.

\section{Systematic translational analysis of aversion-related circuitry}

The present hypothesis is that there exists a core aversion-related circuit involved in processing aversive stimuli regardless of whether they are painful or nonpainful. In an analogical sense, this network would be similar to the basic underlying (e.g. mesocorticolimbic) circuitry identified in the field of reward [21-23]. Prior meta-analyses in humans have outlined core regions associated with pain processing $[6,24]$, and some animal work has even suggested the existence of an overlapping pain and non-pain-related aversion network [25]. Nonetheless, no investigations have used both human and animal data to directly explore the possibility of a shared network for pain- and non-pain-related processing.

To this end, a translational cross-species approach was used to identify the core components of the potential aversion-related network. More specifically, our first aim was to compare brain activations to the passive reception of painful aversive stimuli in healthy adults (using a meta-analysis of human imaging data; i.e. functional magnetic resonance imaging, fMRI, or positron emission tomography, PET) to those in rodents (using a systematic review of studies including markers of cellular activation and available imaging studies). Secondly, we aimed to compare the results on pain-related processing to those gathered previously on the processing of passive non-painful aversive stimuli in humans (meta-analysis) and animals (systematic review) [5].

Our main hypothesis is that aversive stimuli, regardless of origin (e.g. sensory modality) or perception (e.g. painful or non-painful), are processed largely by a common network of brain regions. However, some areas may be more (or uniquely) involved in different aspects of painand non-pain-related aversive processing. The use of a meta-analytical approach allows for the clear distinction of areas which have been identified reliably across numerous studies - in comparison to individual studies which may have low power and a higher probability of reporting false positive activations [26]. The incorporation of animal studies allows for a cross-species comparison and ensures that especially subcortical areas, which may be important for aversion-related processing, are identified. Studying these areas in humans has proven difficult given limitations in optimal imaging resolution and the correct interpretation of subcortical activations (or the lack thereof) [27]. Importantly, this translational approach allowed for the direct comparison of the overlap between areas identified in pain and nonpain aversion studies.

\section{Results}

Pain-related activation in humans (meta-analysis) and rodents (systematic review)

Results of the meta-analysis revealed a general painrelated brain circuitry involving the bilateral insula, mid cingulate cortex (MCC), postcentral gyrus (primary and secondary somatosensory cortices), precentral gyrus (motor cortex), secondary/supplementary motor area (SMA), and thalamus (Thal). Additional extent-based clusters, extending from regions with peak activations, were also noted in the anterior cingulate cortex (ACC), posterior cingulate cortex (PCC), dorsomedial prefrontal cortex (DMPFC), bilateral operculum, bilateral supramarginal gyri, right ventrolateral orbitofrontal cortex (VLOFC), right rostral temporal gyrus (RTG), right hippocampal/parahippocampal area (Hipp/Parahipp), inferior frontal gyrus, dorsal striatum (DS), cerebellar cortex, and midbrain and rostral pons (Figure 1 and Additional file 1: Table S1A).

As revealed by a systematic review of the non-human animal literature which is summarized in Table 1, all of these areas have also been implicated in animal studies of pain, with the exception of areas corresponding to the 


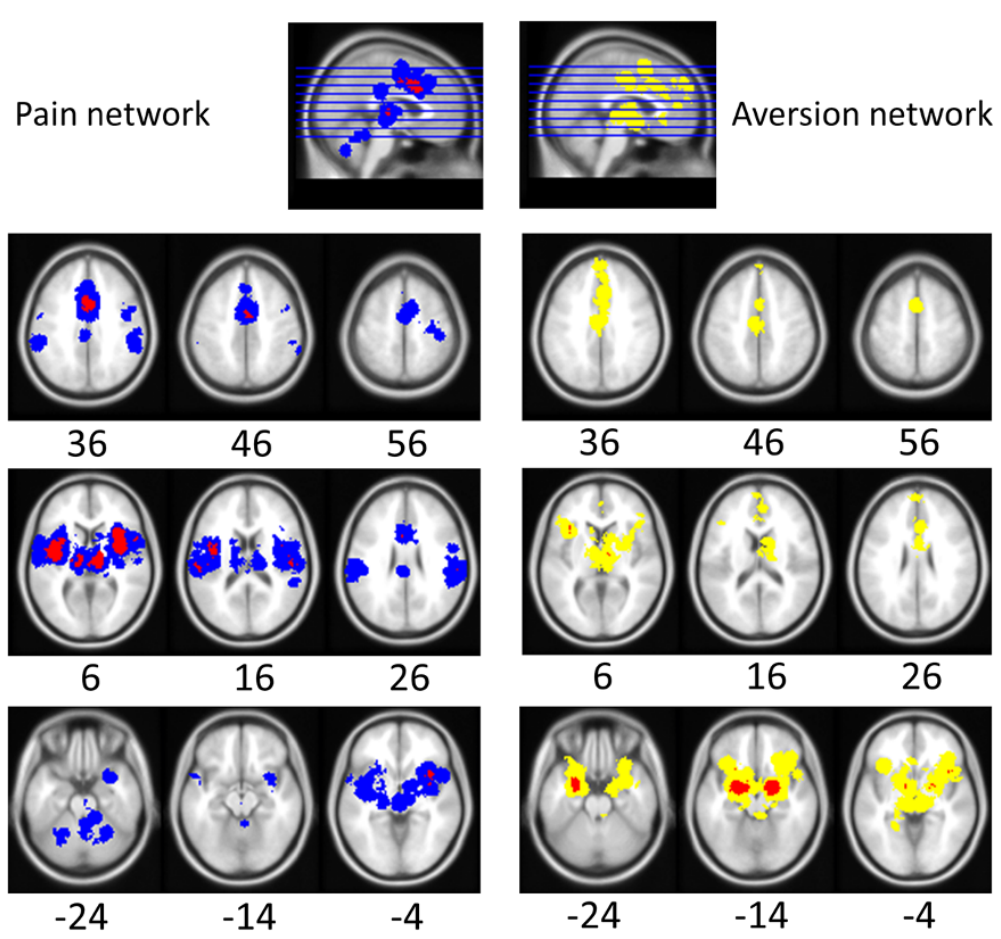

Figure 1 Pain and aversion networks in humans. Results of meta-analysis for human pain-related (left) and aversion-related (right) studies. Pain-related (left) activations (see Additional file 1: Table S1A for related coordinates): Red represents peak voxels in a local neighbourhood, blue represents significant extended clusters. Aversion-related (right) activations (see Additional file 1: Table S1B for related coordinates): Red represents peak voxels in a local neighbourhood, yellow represents significant extended clusters. All results are family-wise error rate whole-brain corrected at $p<0.05$. Numbers below each axial section represent the $Z$ coordinates. The anatomical reference space is MNI 152 (i.e. the average of 152 healthy MRI brain scans). The aversion network was previously reported by [5] and is reprinted here with permission from Frontiers in Integrative Neuroscience.

supramarginal gyrus and rostral temporal gyrus. Additional subcortical areas, not predominantly found across human studies, have also been noted and include the amygdala, bilateral hippocampus/parahippocampal areas (Hipp/Parahipp), septal area, nucleus accumbens (NAc; a major part of the ventral striatum, VS), bed nucleus of the stria terminalis (BNST), piriform cortex, and retrosplenial cortex, as well as areas of the midbrain (i.e. periaqueductal grey (PAG), superior (SC) and inferior (IC) colliculi, habenula (Hab), raphe nuclei, pretectal area, and red nucleus) and of the brain stem (i.e., nucleus of the tractus solitaries (NTS), parabrachial nucleus (PBN), locus coeruleus (LC)). For individual study details and inter-study comparisons, see Additional file 1: Table S2A.

\section{Non-pain-related aversive brain activation in humans and other animals}

As published previously by Hayes \& Northoff (2011), the meta-analysis results of human neuroimaging studies using passive non-painful aversive stimuli implicated brain circuitry involving the amygdala (Amyg), anterior insula (AI), ventrolateral orbitofrontal cortex (VLOFC), hippocampus (Hipp), and parahippocampal gyrus (Parahipp), dorsal striatum (DS), rostral temporal gyri (RTG), and thalamus (Thal). Extent-based clusters were also noted in the anterior and middle cingulate cortex (ACC and $\mathrm{MCC}$ ), dorsomedial prefrontal cortex (DMPFC), secondary motor area (SMA), and midbrain (Figure 1 and Additional file 1: Table S1B) [5].

Animal studies involving non-painful aversive stimuli implicated all of the same regions shown in humans, except the rostral temporal gyri specifically (see Table 2). In addition, subcortical areas such as the bed nucleus of the stria terminalis (BNST), habenula (Hab), hypothalamus (Hyp), nucleus of the solitary tract (NTS), nucleus accumbens (NAc), periaqueductal grey (PAG), parabrachial nucleus (PBN) and septal nuclei were also noted. For individual study details see Additional file 1: Table S2B.

\section{Comparison between pain- and non-pain-related activations in humans and animals Conjunction and contrast analyses in humans}

A conjunction analysis of the human meta-analysis results for pain- and non-pain-related aversive stimuli revealed a common network of brain areas including: $\mathrm{MCC}$, posterior cingulate cortex (PCC), $\mathrm{AI} /$ claustrum, 
Table 1 Major brain activations in 32 pain non-human animal studies

\begin{tabular}{lll}
\hline \multicolumn{4}{c}{ Rank order: Pain (32 studies) } \\
\hline Area & $\begin{array}{l}\text { Studies } \\
\text { reporting } \\
\text { activation }\end{array}$ & Percentage \\
\hline Cingulate & 15 & $47 \%$ \\
\hline Thal & 14 & $44 \%$ \\
\hline Sens & 13 & $41 \%$ \\
\hline Hyp & 12 & $38 \%$ \\
\hline Amyg & 9 & $28 \%$ \\
\hline PAG & 9 & $28 \%$ \\
\hline DS & 9 & $28 \%$ \\
\hline Motor & 7 & $22 \%$ \\
\hline Ins & 7 & $22 \%$ \\
\hline Hipp/parahipp & 6 & $19 \%$ \\
\hline NTS & 5 & $16 \%$ \\
\hline IC & 5 & $16 \%$ \\
\hline LC, PBN, Pretectal area, SC, Septal area & 4 each & $13 \%$ \\
\hline Hab, NAc, Raphe, Piriform, & 3 each & $9 \%$ \\
\hline PFC(IL/PL)/OFC, Visual ctx & & $6 \%$ \\
\hline Aud ctx, BNST, Cerebellum, Retrosplenial & 2 each \\
\hline Red n & 1 & $3 \%$ \\
\hline Results ar ofere by the numbr of studes & & \\
\hline
\end{tabular}

Results are ordered by the number of studies reporting specific activations; percent of studies reporting activations is used for comparative illustration. For individual study details and inter-study comparisons, see Additional file 1: Table S2A.

right VLOFC, DMPFC, right RTG, SMA, thalamus, right Hipp/Parahipp, dorsal striatum, and midbrain (see Figure 2, Table 3). We used the conservative minimum statistic resulting in the intersection of 5900 voxels at the cluster-based FWE corrected level [28]. While all clusters are displayed in Table 3, only those greater than 10 voxels were considered in the discussion. The percentage of overlapping voxels in the present study accounted for $24 \%$ of pain-related activations and $35 \%$ of aversion-related activations.

In addition to the activation of this common network, the presentation of painful compared to non-painful stimuli (painful $>$ non-painful) resulted in additional unique activations in the primary and secondary sensorimotor cortices, posterior cingulate cortex (PCC), the bilateral operculum (including bilateral SMG), cerebellum, and the rostral midbrain (in a region consistent with the VTA; see [29]) and rostral pons (see Figure 2).

Alternately, non-painful $>$ painful aversive stimuli resulted in unique activations in the amygdalae and left hemisphere VLOFC, RTG, and Hipp/Parahipp. In addition, extended activation clusters unique to nonpainful stimulus presentation were noted for the more anterior portions of the ACC (pregenual and subgenual $\mathrm{ACC}$ ), the DMPFC, a more anterior portion of the PCC/ posterior $\mathrm{MCC}$, an area encompassing the hypothalamus
Table 2 Major brain activations in $\mathbf{4 2}$ aversion non-human animal studies

\begin{tabular}{lll}
\hline Area & Rank order: Aversion (42 studies) \\
\hline Amyg & $\begin{array}{l}\text { Studies } \\
\text { reporting } \\
\text { activation }\end{array}$ & $\begin{array}{l}\text { Percentage of } \\
\text { studies reporting } \\
\text { activation }\end{array}$ \\
\hline Thal & 32 & $76 \%$ \\
\hline Hyp & 13 & $30 \%$ \\
\hline NTS & 12 & $29 \%$ \\
\hline Parahipp/Hipp & 10 & $24 \%$ \\
\hline PBN & 9 & $21 \%$ \\
\hline PAG & 8 & $19 \%$ \\
\hline Ins & 8 & $19 \%$ \\
\hline PFC (PL, IL)/OFC & 7 & $17 \%$ \\
\hline BNST & 7 & $17 \%$ \\
\hline NAC & 5 & $12 \%$ \\
\hline Septal & 5 & $12 \%$ \\
\hline ACC, DR, DS, LC & 3 & $7 \%$ \\
\hline Motor, Hab, VTA & 2 each & $5 \%$ \\
\hline
\end{tabular}

Results are ordered by the number of studies reporting specific activations; percent of studies reporting activations is used for comparative illustration. For individual study details and inter-study comparisons, see Additional file 1: Table S2B. Reprinted with permission from Frontiers in Integrative Neuroscience [5].

and dorsal (DS) and ventral striatal (VS) areas, left SMA, and bilateral VLOFC (Figure 2).

\section{Comparison to non-human animals}

While a conjunction analysis was not performed across non-human animal studies (given that precise coordinates related to neural/cellular activation are less often given), the pattern of activation seen in humans was reflected in these studies. The general pattern of brain activation between humans and animals appears to be maintained, as is generally reflected by the relative percentage of studies reporting such activations (see Tables 3A and 3B). For instance, a large percentage of animal studies have reported cingulate activations in pain-related studies (Table 1) which is mirrored by the large activation in the pain (but not the non-pain) metaanalysis; in comparison, a majority of animal studies have reported amygdala activations in response to nonpainful aversive stimuli (Table 2), which is reflected by the large activation in the non-pain (but not the pain) meta-analysis results.

Additional subcortical regions of importance (which may be too difficult to detect or differentiate precisely using human brain imaging techniques) have also been noted in animals (see Tables 1, 2). Most seem to be involved in general aversion-related processing (i.e. BNST, Hab, Hyp, LC, NAc, NTS, PAG, PBN, septal area, anterior raphe nuclei) while this investigation suggests 


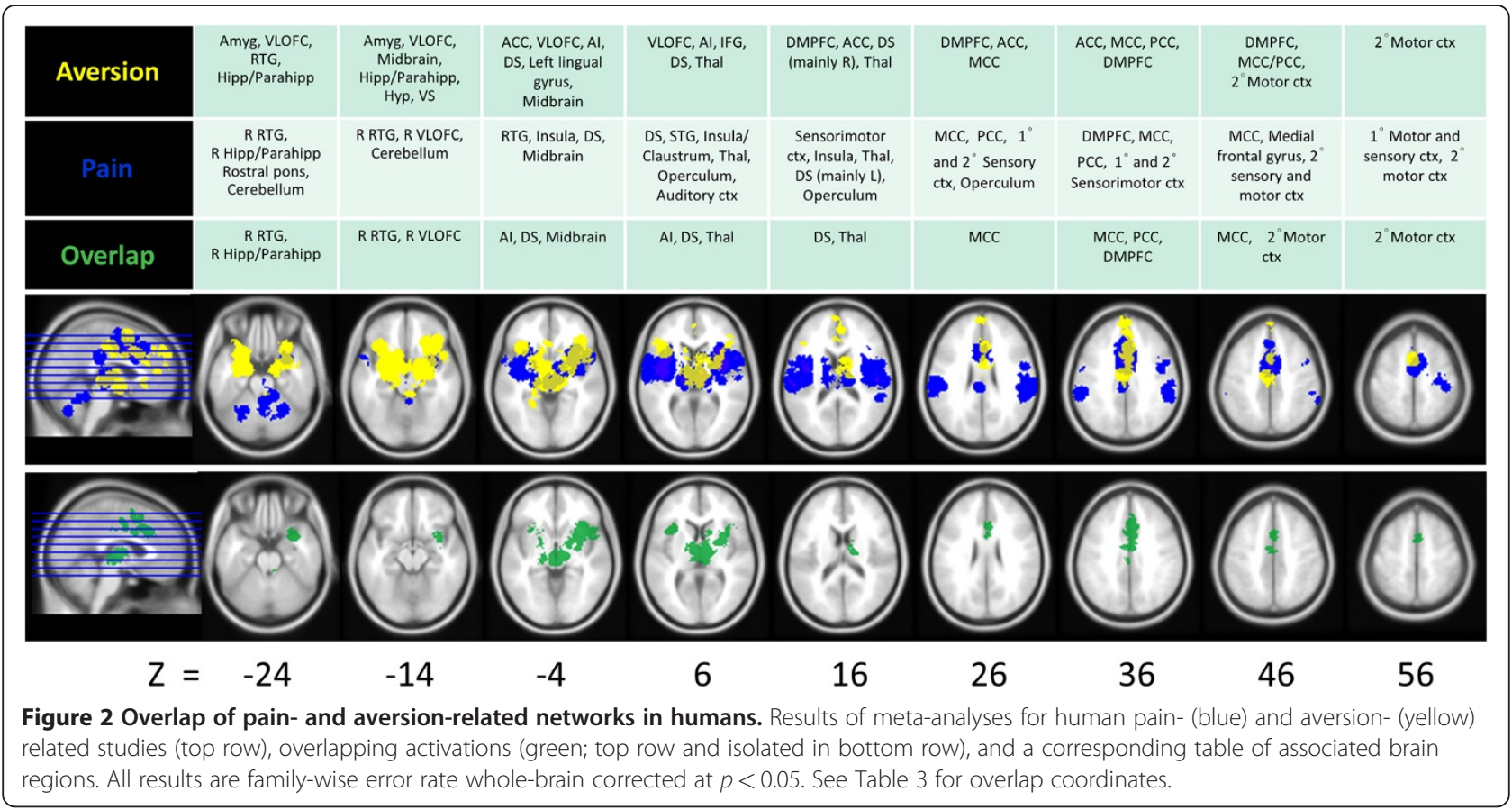

that some may be involved more in pain- (i.e. IC, SC, pretectal area, red nucleus, retrosplenial area) or nonpain-related (i.e. basolateral and central nuclei of the amygdalae, VTA) processing. Results for overlapping and non-overlapping activations across species are illustrated in Figure 3.

\section{Discussion}

The present work aimed to further define a network of brain regions involved in the general processing of aversive stimuli (both pain- and non-pain-related) using a cross-species translational approach. A direct comparison was made between studies investigating the passive reception of painful versus non-painful aversive stimuli in humans (using a meta-analysis; Figures 1 and 2) and rodents (using a systematic review; Tables 1 and 2).

Firstly, it was found that regions associated with the processing of painful aversive stimuli (Figure 1, Additional file 1: Table S1A) and those noted previously with non-painful aversive stimuli (see [5]; Figure 1, Additional file 1: Table S1B) are similar across humans and other animals (Tables 1,2). The value of including animal data is that they help support and extend the results noted in humans (see further discussion below). Secondly, it was shown in humans (Figure 2, Table 3) and other animals (Tables 1 and 2, also see Additional file 1: Tables S2A and Additional file 1: Table S2B) that most regions show spatially overlapping involvement for the processing of both painful and non-painful aversive stimuli.

Together, these data strongly suggest the existence of a core aversion-related network of brain regions which include cortical (i.e. MCC, PCC, AI, DMPFC, RTG, SMA, VLOFC; see results section or abbreviation section for full names) and subcortical (i.e. Amyg, BNST, DS, Hab, Hipp/Parahipp, Hyp, NAc, NTS, PAG, PBN, raphe, septal nuclei, Thal, LC, midbrain) areas. Lastly, although a core aversion-related network was identified, both painful and non-painful stimuli activate additional regions which appear to be non-overlapping, although this is discussed further below (summarized and illustrated in Figure 3).

\section{Areas activated by painful and non-painful aversive} stimuli are similar across species

Results from the pain-related meta-analysis (Figure 1, Additional file 1: Table S1A) and animal literature review (Table 1, Additional file 1: Table S2A) are consistent with prior human [30,31] and animal studies [32,33]. Similar regions were noted here, including: bilateral insula, MCC, primary and secondary motor and somatosensory cortices, VLOFC, Hipp/Parahipp, DS, Thal and midbrain. It is also worth noting that our results are nearly identical to another recent human meta-analysis on pain [24]. Additional, mainly subcortical, areas identified across animal studies included the Amyg, BNST, Hab, Hyp, NAc, NTS, PBN, PAG, SC, IC, and septal nuclei. Brain imaging techniques may be limited by low subcortical resolution (see [34] for a brief discussion of fMRI capabilities), however some fMRI studies focusing on this level (e.g. PAG, PBN, VTA) have corroborated their involvement in human pain processing (e.g. [35]). 
Table 3 Overlap between painful and non-painful aversion-related brain activations in humans studies

\begin{tabular}{llllll}
\hline Cluster & $\mathbf{x}$ & $\mathbf{y}$ & $\mathbf{z}$ & voxels & $\begin{array}{l}\text { Volume } \\
\text { (mm3) }\end{array}$ \\
\hline 1 & 16 & -3 & -1 & 4019 & 32152 \\
\hline 2 & 1 & 9 & 39 & 1418 & 11344 \\
\hline 3 & -33 & 17 & 2 & 400 & 3200 \\
\hline 4 & -2 & -23 & 36 & 20 & 160 \\
\hline 6 & 7 & -38 & -21 & 20 & 160 \\
\hline 7 & -21 & 12 & -3 & 5 & 40 \\
\hline 8 & -24 & -6 & -9 & 3 & 24 \\
\hline 9 & -16 & 15 & -4 & 2 & 16 \\
\hline 10 & 4 & -25 & 38 & 2 & 16 \\
\hline 11 & 9 & -30 & -20 & 2 & 16 \\
\hline 12 & -12 & 18 & 8 & 1 & 8 \\
\hline 13 & -18 & -28 & 0 & 1 & 8 \\
\hline 14 & 8 & 0 & -6 & 1 & 8 \\
\hline 15 & -32 & -2 & -10 & 1 & 8 \\
\hline 16 & -34 & 4 & -12 & 1 & 8 \\
\hline 17 & -12 & 12 & 8 & 1 & 8 \\
\hline 18 & -20 & 6 & 4 & 1 & 8 \\
\hline 19 & 18 & 16 & 0 & 1 & 8 \\
\hline & 4 & -28 & -20 & 1 & 8 \\
\hline
\end{tabular}

Results of MKDA analysis: Overlap for painful and non-painful stimuli highlighted in the bottom row of Figure 2 . All results are family-wise error rate whole-brain corrected at $p<0.05$. Only clusters $>10$ voxels were considered.

As reported previously [5], non-painful aversive stimuli result in consistent activations in humans (Figure 1, Additional file 1: Table S1B) and other animals (Table 2, Additional file 1: Table S2B). The main activations to non-painful aversive stimuli across species include: Amyg, ACC, VLOFC, DMPFC, secondary motor cortex, Hipp/Parahipp, DS, RTG, Thal, and midbrain. Additional subcortical activations, identified most consistently in animal studies (although see human imaging studies for instance by [36] and [37]), included the BNST, Hab, Hyp, NTS, NAc, PAG, PBN and septal nuclei. These results are also consistent with prior studies across species looking at aversion-related concepts such as fear $[38,39]$, threat $[40,41]$ and social punishment $[42,43])$.

Together, these findings suggested the involvement of similar regions in pain- and non-pain-related aversive processing (Figure 1). However, the specific substrates involved remain unclear as does whether the apparent spatial overlap involved in both processing types reflects an actual overlap in function. Iannetti and Mouraux (2010) have argued that the so-called Pain Matrix (reflecting a pain-specific network of brain regions; see $[44,45]$ for early uses of the term) may be misleading. While the Pain Matrix is activated reliably across studies (as underscored here and in other meta-analsyses, e.g. [24]), and the magnitude of its response is highly correlated with the intensity of pain perception [46,47], there is, nonetheless, presently no evidence that any single brain region or clearly defined network is devoted to the processing of pain.

Iannetti and Mouraux (2010) (and other authors, e.g. [13]) subsequently suggested that, instead of painspecific processing, this system may be better regarded as a multimodal network related to the detection of saliency [11]. The notion that this network is largely multimodal is supported by prior work demonstrating activations in these regions regardless of the sensory modality in which the aversive stimuli were presented $[5,12]$. As well, this notion is further supported by the present findings that painful stimuli (which are all tactile in nature) show overlapping activations with mainly non-tactile, non-painful, aversive stimuli. In particular, in a series of fMRI experiments, Mouraux et al. (2011) showed that most of the activations related to painful stimuli appear to also be involved in non-painful processes [12].

In another recent example, fMRI work by Moulton et al., (2011) showed similar overlapping between activations related to non-painful (i.e. unpleasant pictures) and painful (i.e. noxious heat) aversive stimuli in the cerebellum; these signals were correlated with many of the same regions noted in the present study (e.g. Hyp, ACC, Hipp/Parahipp) [48]. Interestingly, it is difficult to assess the cerebellum's potential involvement in general aversion-related processing given that it is often overlooked in imaging studies and most animal studies use painful shock-tone pairing to investigate its role. As such, while its role in general conditioning mechanisms is well established (e.g. [49]), fewer studies have looked at non-pain-related aversive stimuli (though note research showing its involvement in conditioned taste aversion; e.g. [50]).

As the frequent occurrence of similar brain activity appeared to be further supported by the initial crossspecies results above, the second aim of this study was to specifically compare the potential overlap between pain- and non-pain-related activations in humans and other animals.

\section{Aversion-related stimuli activate a common core network}

The conjunction analysis of pain- and non-pain-related aversion studies in humans (Figure 2, Table 3 ) and the systematic review in animals (Tables 1 \& 2; Additional file 1: Tables S2A \& S2B) revealed a common core aversion-related network consisting of MCC, PCC, AI/ claustrum, right VLOFC, DMPFC, SMA, right Hipp/ Parahipp, Thal, DS, and midbrain (including an area encompassing the PAG). Additional, mainly subcortical, areas were noted in animals including the Amyg, BNST, Hab, Hyp, NAc, septal nuclei, NTS, and PBN. This core, 


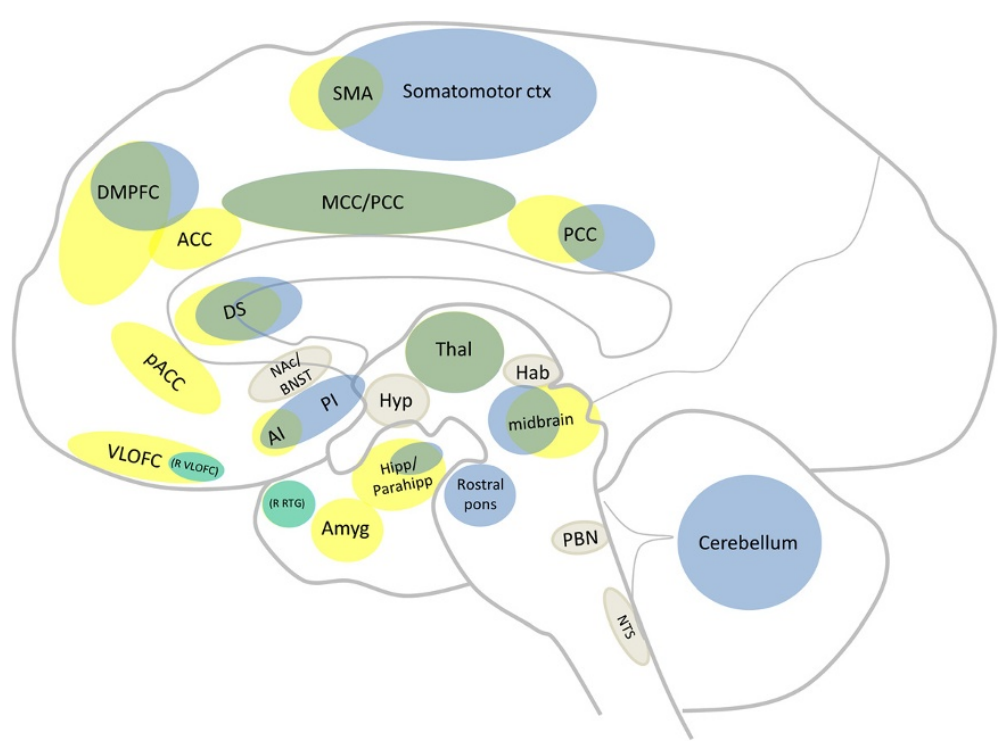

Figure 3 Similarities and differences in pain- and non-pain-related aversive circuitry. Sagittal section of a human brain summarizing the main results across species; illustrating core areas consistent with responses to all pain- and non-pain-related aversive stimuli (green), those responding to painful (blue) or non-painful (yellow) aversive stimuli alone, and regions implicated mainly in non-human animal studies (beige).

cross-species, aversion-related network (illustrated in Figure 3) suggests that passively received aversive stimuli are, at least in part, processed in a similar way using similar neurobiological substrates.

Identified consistently here, both the cingulate (especially the MCC) and bilateral AI have been implicated in many functions though there is still much debate on whether a basic role for these regions exists. For instance, research in humans and other animals suggests they are involved in detecting and processing errors $[51,52]$, in reward-related processing [53,54], and in adaptive decision making $[55,56]$. In fact, given the roles that these, and other, regions play across various networks (e.g. salience, interoceptive, resting state, and valuative), it is possible that they are active participants in many underlying processes. For instance, various lines of evidence in humans and primates have implicated the anterior portion of the MCC as being especially key for the integration of negative affect, pain, and cognitive control (as reviewed in [57]). Moreover, despite our attempt to reduce the impact of cognitive processes by limiting our studies to those involving passive stimuli, it is important to note that implicit cognitive processing (e.g. brain activity related to preparatory escape, emotional regulation) may contribute to the activations noted across species.

\section{Involvement in salience network}

For instance, it has been suggested that main role of the ACC might be learning and predicting the outcome of actions, regardless of valence [58] - essentially a processor and predictor of salient/behaviourally relevant sensory stimuli. A human imaging meta-analysis on the role of the insula also suggested that the AI may be an integrator of salient stimuli [59]. The notion that the cingulate and AI are involved in salience processing is also in line with the experimental findings of Mouraux et al. (2011) and Downar et al. (2003) [12,13], as is the involvement of the PCC $[60,61]$ and the somatosensory cortex (though the present meta-analysis suggested this region was selective for painful stimuli). They found that the BOLD signal in these regions corresponded best to the saliency of the aversive stimulus, and not whether it is painful or non-painful (using stimuli across sensory modalities). Indeed, the indication that an upcoming stimulus will be painful (i.e. predictors with high salience) has been found to potentiate signals in traditional pain-related regions (e.g. MCC) $[62,63]$. Along with resting state data showing that the AI is functionally connected to the pACC/MCC [64], these studies strongly support the notion of the cingulate (particularly the $\mathrm{MCC}$ ) and AI as being involved in salience processing $[12,56]$.

Other regions identified in the present study may also be involved in processing salient stimuli, particularly in the preparation and/or initiation of motor control. Structures such as the DS and SMA appear to process preparatory defensive actions (and/or inhibit unwanted responding) related to escaping potential threats [65]. In general, however, the DS responds to the expected value of stimuli (including reward, e.g. [66]; similar to the cingulate and insula) and may be important in changing 
expectations based on past and present contexts [67]. The PAG also responds to highly salient (particularly aversive) stimuli, is a well-known source for descending control over spinal pain pathways [68], and appears to be involved in autonomic-somatomotor integration related to orchestrating defensive behaviours [69]. This integration is achieved via its close connections to Thal, Hyp, AMYG, PFC, and other brain stem nuclei involved in autonomic processing (e.g. NTS, PBN, raphe; as noted across the present animal data) [70]. (For a comprehensive review on the PAG in neuroimaging studies see [71].) Considered together, the cross-species data noted here suggest that the core regions in general aversive processing may be involved in processing salience information. This is in line with the findings from Mouraux et al. (2011), who suggested that these regions form a salience (as opposed to a pain) network [12].

\section{Involvement in interoceptive network}

The AI and ACC/MCC are also considered key components of a circuit mediating interoceptive awareness. Studies have shown that both the insula and ACC/MCC are involved in processing the interoceptive awareness of stimuli (e.g. heartbeat, respiration; e.g. [72]), while animal studies have demonstrated similar roles (e.g. [73]). Menon and Uddin (2010) take a network perspective describing these regions as core components of a salience network which act as integrators of overlapping networks (carrying information related to interoception, homeostasis, working memory, higher-order control processes) [74]. Additionally, the authors posit that the activity of these hub regions and the interaction between them may be involved, partly, in choosing/switching between relevant task-related and resting state networks (e.g. engaging task-relevant memory and attentional processes while disengaging from non-task-related activity). The notion of the ACC/MCC and insula as a key integrator network is also supported by others (e.g. [64]) who have noted functional connectivity between AI-pACC/ MCC (which they suggest may integrate interoceptive and emotional information) and between insula-MCC (which may be more involved in exteroceptive processing and response selection).

\section{Involvement in resting state networks}

The baseline activity of the brain is essential in determining the relative stimulus-induced activation in both animal and human studies. As such, how the baseline is defined conceptually and experimentally may ultimately affect the results (see [75,76] for further discussion). As noted in the Methods section, most of the animal studies included here necessarily use between-subjects measures, whereas the human neuroimaging studies typically use within-subjects measures - suggesting that the baselines may be quite different. As such, caution should be taken when interpreting the results across species. Nonetheless, the animal neuroimaging studies included here (e.g. $[77,78])$ are able to help bridge the gap somewhat and their findings are congruent with the other studies. Moreover, human imaging studies are more often including a baseline (or so-called resting state) period in their designs (in which the subject is instructed to stare at a fixation cross or close their eyes and not focus on any particular thoughts), which results in the identification of baseline or resting state brain activity.

Given the apparent overlap and interactivity between these resting state regions (e.g. VMPFC/pACC and PCC) and exteroceptive/salience regions, some authors have recently explored their potential relationship. For example, one recent study investigated the potential relationship between resting state activity (within the default mode network) and emotion- and intero-/exteroceptive-related activity [79]. They demonstrated that increased activity in the default mode regions (e.g. VMPFC/pACC, PCC) during rest was associated with decreased emotional perception ability, without any noted relationships to the perception of intero-/exteroceptive stimuli. This raises the question of whether the activity, particularly in the MCC, is selective for salience or rather for value-related processing (related to determining the positive or negative value of a stimulus). Moreover, it questions whether different regions of the cingulate (or similar regions activated differentially across time) are involved separately in processing salience-, emotion-, and interoceptive-related information (e.g. [64]).

\section{Involvement in valuative network}

Finally, recent reviews of the reward literature for both humans [80] and animals [23] describe many of the same regions noted here for the aversion-related network. This raises the issue of whether, and to what degree, the core aversion-related regions noted in the present study are involved in aversion-specific (not reward-related) processing. If both aversion- and rewardrelated activity are found equally in these regions, this would provide further support of a salience network. However, if different regions are involved in each, and/or to different degrees, this would suggest the existence of interacting, or even separate, neural networks for processing value-related information. While there are, to our knowledge, no meta-analyses or systematic reviews outlining the similarities and differences for reward- and aversion-related brain activity, a number of studies (particularly at the neuronal level) have suggested that perhaps both salience-selective and value-selective processing occur in both overlapping and separate networks.

For instance, many animal (e.g. [81]; and see [20] for review) and some human studies (e.g. [36,37] and see 
[82] for review) have implicated the NAc in coding both aversive and rewarding states. Lammel et al. (2011) showed that among dopamine cells of the VTA there appear to be many distinct (reward-, aversion-, or saliencyrelated) populations defined by receptor/channel type, activity, location and density, and axonal projections [83]. Another study demonstrated that while the dopaminergic modulation of the basal ganglia's direct striatonigral and indirect striatopallidal pathways are involved in both processing types, primary activation is shifted to the indirect pathway during aversion-related processing [84]. Furthermore, single-unit ACC recordings in four humans viewing emotional pictures showed that of cells responding, most were selective for general aversionrelated stimuli - although some cells responded to both aversive and rewarding stimuli [85]. These findings help explain how a regional population of cells can contribute to differential processing (e.g. aversion and reward).

Taken together, these results support the existence of a core group of brain regions involved in basic aversionrelated processing (Figure 3); the inclusion of nonhuman animal data has helped confirm and further extend these findings (mainly regarding subcortical regions). The evidence suggests that components of this network are involved in processing various types of information (e.g. saliency, interoception, valuative). Future neuroimaging studies should consider parsing, for instance, value and salience (e.g. using multi-levelled stimuli, to investigate 'dose-response-like' curves) as has been attempted in some behavioural experiments [86]. Though the focus has been on the overlap between pain- and non-pain-related aversive processing, it should be noted that some activations (particularly in the metaanalysis) appeared to be selective for painful over nonpainful stimuli (and vice versa). These activations are discussed briefly in the following section.

\section{Differential activations related to painful and non-painful aversive stimuli}

Although a core network of brain regions for the processing of painful and non-painful aversive stimuli was identified, the areas of activation noted in the human meta-analysis do not overlap completely. In fact, there are a number of regions which appear to be unique to painful or non-painful stimuli. Specifically, painful stimuli resulted in unique activations in the primary and secondary sensory cortices, the PCC, bilateral operculum/ mid and posterior insula, and cerebellum. Non-painful aversive stimuli resulted in unique activations in the AMYG, L VLOFC, L RTG, and L Hipp/Parahipp as well as additional extended activations in the pACC, DMPFC, HYP, posterior MCC, DS/VS, and bilateral VLOFC. Similar subcortical regions were identified in animal studies of both pain- and non-pain-related processing (e.g. NTS, PBN, BNST). Nonetheless, from the animal studies included here, a few areas are noted in only pain- (i.e. red nucleus, pretectal area, IC/SC) or nonpain- (i.e. VTA) related studies.

The differences may in fact be unique, thus providing unique neural signatures for painful and non-painful aversive stimuli. However, there are alternative explanations for these apparently unique activations which seem more tenable. Firstly, the differential weighting of activations (i.e. that some regions are more involved) may help explain the absence of activations in human studies on pain (e.g. amygdala) compared to non-pain aversion. Secondly, as the analysis of imaging studies on pain and non-pain aversion were limited to the passive reception period, this is equivalent to taking a temporal snapshot of brain activity. While intended to be similar across pain and non-pain studies, this snapshot may in fact reflect unique brain processing for two types of stimuli differentiated by their timing properties (i.e. painful stimuli result in fast aversive responding; non-painful stimuli are slower and more variable).

\section{Differential weighting}

That nearly all regions were noted in both animal studies of pain and non-pain aversion (Tables 1 and 2; e.g. involvement of the amygdala, [32,87]) supports the notion that entirely unique activations for either are rare or unlikely. However, a differential weighting of activations may be reflected in the ranking of regions in animal studies (Tables 1 and 2), which generally reflect the core regions noted in the human meta-analysis (Figure 2). For instance, the amygdala is activated more consistently in non-pain imaging studies, whereas the cingulate and sensory cortex appear more involved in pain studies (Figure 1). However, these rankings (i.e. the percentage of animal studies noting specific brain activations) should only be considered illustrative, as animal studies typically choose regions a priori (compared to a whole-brain approach). Findings for a set of regions may lead to a disproportionately higher investigation rate by other researchers, which can inflate or mask the relative importance of some regions (though brain imaging is also not immune to such biases; see [88] for a brief discussion of this in relation to meta-analyses). Nonetheless, most animal studies included here investigated $\geq 5$ brain regions, and the results are similar to those in humans and other animals (including studies investigating other aversion-related concepts such as fear [39], threat [41] and social punishment [43].

\section{Differential temporal dynamics}

Another potential explanation for differences between pain and non-pain aversion includes the timing of activity, as noted above. While the temporal dynamics of this 
circuitry have not been worked out, conditioning studies in animals $[89,90]$ and humans [91,92] have suggested temporal and/or subregional differences between the processing of conditioned stimuli predicting an aversive stimulus and the reception itself (underscoring the importance of spatio-temporal dynamics). For instance, the amygdala is known to be more involved in assessing the expectation (especially involving the timing) of aversive stimuli [93,94] - though see [95] for an fMRI study in which long stimulation periods of pain perception resulted in amygdala activation. Another study by Guimarais et al. (2011) showed that increasing the time interval between a predictive tone and a shock changed the involvement of some structures in rats [96]. For instance, at $\sim 5 \mathrm{~s}$ intervals, the mPFC became more active, whereas at longer $(\sim 40 \mathrm{~s})$ intervals, dorsal hippocampal activity became necessary for learning about the aversive stimulus. Nonetheless, it is difficult to compare the results from animal studies directly to those in human imaging (especially without direct translational mapping), and further study on the temporal aspects of aversive processing should be undertaken.

\section{Strengths and limitations}

The greatest strength of the current work is its translational nature. The inclusion of animal studies has two main advantages. Firstly, they help to support the findings from human imaging and add insight regarding subregional differences and underlying mechanisms. Secondly, they underscore the involvement of many subcortical regions which are generally underreported in imaging studies (as noted previously). We believe using this approach somewhat offsets the potential selection biases which may be found across human imaging studies (e.g. lowering statistical thresholds for a priori regions) and animal studies (e.g. looking only for activity in a priori regions; also see below).

The strict and narrow criteria used in both human and animal studies allowed for a clearer interpretation of results (e.g. the use of passive and acute aversive stimuli only; the exclusion of studies/subjects using explicit cognitive tasks; see Methods section for all criteria). These criteria were used to isolate, as clearly as the present methods allow, the period of brain activation during which acute aversive stimuli are present (e.g. most neuroimaging studies look at periods around 5-10 seconds; the animal studies included here extract the brains as soon as possible following stimulus presentation) - thus, attempting to separate this period from others (e.g. anticipation, termination). It is in this sense that we have attempted to identify a network associated with aversion-related processing (see also [26] for further discussion on using meta-analyses to identify functionally related brain regions). Nonetheless, it is worth pointing out again (as discussed briefly above in the Differential weighting and Differential temporal dynamics sections) that the inference of a temporal relationship between regional activations relies heavily on the inclusion, and exclusion, of appropriate studies. Ultimately, the identification of such networks through meta-analyses and systematic review should be used as the basis for testing future hypotheses regarding co-activation.

This approach also shed some light on one inherent and important limitation of meta-analyses - particularly those using human imaging studies. While some neuroimaging studies do report subcortical activations in aversion-related processing (e.g. $[37,97,98])$, their relative scarcity means some subcortical regions may not be noted in the final meta-analysis results. This absence of activation likely also extends to highly variable cortical regions. The corollary is that meta-analysis results underscore the most consistent nodes of activation across studies (with the coordinates being more informative than the size or shape of the clusters per se; see also Differential weighting discussion above), while regions not identified may still be active (and even essential) components - findings that are made clearer through animal studies looking directly at brain tissue.

Although the results of the animal studies outlined in Tables 1 and 2 (i.e. listing the percentage of reported brain activations) should be considered illustrative due to reporting and researcher interest biases and the lack of a whole-brain approach (as insisted upon for the imaging data), most studies investigated at least 5 brain regions. In fact, only 9 of the 42 non-pain-related studies [89,90,99-106] and 13 of the 32 pain-related studies [87,107-118] focused on 4 or less regions. In addition, none of the pain-related studies focused solely on the cingulate (a key node identified in both human and animal data), and only 3 studies from the non-pain-related aversion studies $[100,105,106]$ focused solely on the amygdala (perhaps the single best described aversionrelated region). Although the issue of selection bias and the reporting of positive data (the so-called file-drawer problem) cannot be fully accounted for, taken together, the animal and human data allow for a more confident interpretation regarding the inclusion of brain areas involved in aversion-related processing.

\section{Conclusions}

The results from this translational approach strongly suggest that humans and animals have a common core aversion-related network, consisting of similar cortical and subcortical regions. This work extends from previous work [5] by demonstrating that most of the regions typically associated with a pain network are involved in the generalized processing of all aversive stimuli to some extent. While saliency may be an integral factor to which 
this network responds, it seems unlikely that it should be thought of as a saliency detector - particularly given the apparent incomplete overlap of activations for painful and non-painful stimuli, as well as for that of rewarding stimuli. The differential weighting found between pain- (e.g. higher activations in MCC and posterior insula) and non-pain- (e.g. amygdala) related processing suggests that aversion-related concepts may rely on the use of similar substrates (i.e. aversion-related network) but to varying degrees and perhaps over different timescales - thus underscoring the need for the investigation of spatio-temporal dynamics within this network.

\section{Methods}

\section{Painful and non-painful aversion-related brain activation} in humans

Literature search: We identified all imaging studies positron emission tomography (PET) and functional magnetic resonance imaging (fMRI) - published from 2000 to August 2011 with PubMed (http://www.pubmed. gov) and Web of Science (http://apps.webofknowledge. com; though no additional studies were found here) searches. Keywords included "aversion", "aversive", "avoidance", "punishment", "reinforcement" (to capture some studies focusing on reward, but also using an independently analysed aversive control condition), "fear", "anger", "disgust", "sadness", "negative emotion", "pain", "nociceptive", "unpleasant", "positron emission tomography", and "functional magnetic resonance imaging" and others. Furthermore, we searched the reference list of articles and reviews, including meta-analyses (for example see $[6,119,120])$. The data regarding brain activations associated with non-painful aversive stimuli were reported previously in [5].

Inclusion and exclusion criteria: Our main goal was to compare the basic brain activity of painful- and nonpainful aversive stimuli. Therefore, we included only those studies which used the passive presentation of acute aversive stimuli (e.g. the viewing of unpleasant pictures; exposure to painful stimuli) without active responses. Without behavioural measures, aversive experiences were determined subjectively and often supported through physiological measures such as electrodermal activity. Designs whose contrasts did not include specific comparisons relevant to the current analysis (i.e. involving the passive reception of painful or non-painful aversive stimuli, independent of explicit cognitive processes, memory, or attention) were excluded. In addition, only studies that reported coordinates from whole-brain analysis were included (although some studies discussed regionof-interest data, those coordinates were not included here). These criteria lead to the inclusion of studies involving both exteroceptive (e.g. pictures, shock) and interoceptive (e.g. rectal distension) aversive stimuli.
Although the related search terms were included for completeness, studies reporting the responses to specific negative emotions (e.g. sadness, anger) were excluded given their social nature as were other stimuli which may involve ambiguous interpretations such as those involving empathy, disgust, or physical contamination. For related examples involving such analyses showing results consistent with the present study, see $[121,122]$. Other studies looking explicitly at social aspects of aversion, such as social exclusion, were also excluded given that they typically require complex behavioural responses and involve other potentially confounding processes such as empathy and theory of mind. Moreover, it is important to note that most studies involving conditioned fearful stimuli in both humans and animals were excluded to avoid issues related to recent learning effects and complex conditioning designs, although it should be noted that the aversive stimuli used are virtually identical to those included here and the results from such studies are largely similar to those reported here $[123,124]$. Finally, studies involving manipulations in homeostatic states (e.g. hunger, thirst) were also not included given their non-acute nature (e.g. usually involving forced deprivation over time). Although we aimed to cast as large an initial net as possible for both the human and other animal studies, we must concede that, given the conceptual complexity of aversion-related terms, we may have overlooked some studies which do not employ standard terminologies.

We screened all the articles for Talairach or Montreal Neurological Institute (MNI) coordinates and tabulated the reported regional foci. We included the data of healthy subjects only. Studies including individuals with psychiatric illnesses, or a history thereof, those with volumetric abnormalities or brain injuries, those taking any medications or illicit drugs, and those belonging to a group that may result in a sample bias (e.g. war veterans) were excluded. In addition, a large number of studies were excluded due to the absence of coordinates, identification of coordinate systems, and/or incomplete statistical information. These criteria resulted in the selection of 34 non-pain-related studies which included 44 contrasts, and 27 pain-related aversion studies which included 32 contrasts (see Additional file 1 for study references included in the meta-analysis). Regions were labelled macroanatomically by the probabilistic HarvardOxford atlas. The nomenclature for the cingulate by Vogt (2005) was used here [125].

Multilevel kernel density analysis (MKDA) metaanalytic technique: The MKDA meta-analytic approach has been covered in depth elsewhere $[26,126]$. Briefly, MKDA is a coordinate-based meta-analytic method which determines the activation probability of each voxel and contiguous voxel clusters (to create voxel-based and 
cluster-based study comparison maps, respectively) across the brain. Compared with other meta-analysis methods, MKDA prevents any single study reporting a large number of activations from biasing the results (i.e. the study is the unit of analysis) and weights contrasts based on the quality of the study (e.g. random vs. fixed effects) and the sample size. It should be noted that study-specific statistical thresholding is not taken into account, however, because weighting activation peaks by their respective Z-scores introduces the presupposition that the scores across studies are comparable, which is untrue (e.g. scores from studies with small sample sizes would be inflated relative to the larger population; [26] for further discussion and examples). All results are reported in MNI space; co-ordinates from studies using Talairach space were converted to MNI space in the MKDA software using the Brett transform (http://imaging.mrc-cbu.cam.ac.uk/downloads/MNI2tal/tal2mni.m). Peaks from each study were convolved with a spherical kernel of $10 \mathrm{~mm}$ radius; doing so ensures that multiplenearby peaks are not counted as multiple activations (additionally helping to reduce the impact of studies employing lower statistical thresholds and which typically report a greater number of activated voxels). This approach also ensures that single studies do not drive the results of the meta-analysis. The threshold for significance was determined using a Monte Carlo simulation with 3000 iterations (5000 iterations did not alter the results) and a null hypothesis which assumes that the activated regions within each map are not spatially consistent (i.e. that the cluster centers are randomized throughout the grey matter). The voxel size was $2 \times 2 \times$ $2 \mathrm{~mm}$ (i.e. 1 voxel $=8 \mathrm{~mm}^{3}$ ) and cluster sizes were all greater than 10 voxels $\left(>80 \mathrm{~mm}^{3}\right)$. We have reported peak voxel-wise activations as well as peak cluster-wise activations (which include contiguous voxels significant at $p<0.001$; whole-brain FWE corrected). All results are family-wise error rate whole-brain corrected at $p<0.05$. Analyses were performed in Matlab 2009a (Mathworks, Naticks, MA) using MKDA software created by Tor Wager (http://www.columbia.edu/cu/psychology/tor/).

\section{Painful and non-painful aversion-related brain activation in animals}

Literature search: PubMed (http://www.pubmed.gov) and Web of Science (http://apps.webofknowledge.com; again, no additional studies were found here) searches identified rodent studies related to pain-related $(\sim 700$ studies) and non-pain-related ( 350 studies) aversion published in English from 2000 to August 2011. Keywords were similar to those above but also included specific terms related to animal studies such as: "immediate early genes", "IEG", "c-fos", "rat", "mice”, "monkey", "mammal", "avoidance", "fear", "threat", "electrophysiology".
Of the total studies identified, only those clearly showing altered brain metabolism (e.g. increased/decreased c-Fos or blood oxygenated level dependent activity, or BOLD) were included in the systematic review (i.e. 34 pain and 42 non-pain aversion studies). Due to lack of methodological instruments, absence of precise standardized coordinate systems, and the wide range of experimental procedures, we did not conduct the same rigorous metaanalysis in animals as in humans. As with the human data, the non-human animal data regarding the presentation of passive non-painful aversive stimuli were reported previously in [5].

Inclusion and exclusion criteria: We looked at the following metabolic indexes of non-human animal brain activity: immediate early gene activation (e.g. c-Fos or Fos-like expression), BOLD activity in fMRI, [14 C]-2deoxyglucose, and [14 C]-iodoantipyrine. Each of these indexes has previously been related to neural activity and/or metabolism. Considering the broad spectrum of animal models of aversion-related behaviour (e.g. formalin-induced nociception, foot shock, conditioned taste aversion etc.), we looked at all those data that report clear effects in brain activity between control animals and those exposed to painful and/or non-painful aversive stimuli. It is important to note that some methods must necessarily use between-subjects measures (e.g. counting IEG-stained cells in brain slices) whereas others use mainly within-subjects measures (e.g. neuroimaging).

Studies involving adolescent animals, chronic exposure to aversive stimuli, and exposure to drugs of abuse and those having a direct effect on aversion- or rewardrelated brain circuitry, were excluded (although nondrug-exposed controls were included where appropriate). This was done in order to avoid confounding issues related to neurodevelopment and drug interactions and/ or drug-induced changes in brain structure or function unrelated to the acute aversive treatment. Studies using electrical/chemical lesions or other irreversible alterations (e.g. the use of knock-out or transgenic rodents, animals bred for psychiatric disorder-related phenotypes; although one study using rats bred for high or low anxiety levels, though not pre-exposed to anxiolytic stimuli, was included [127] as the results following an aversive probe largely converged regardless of anxiety levels) were also excluded for clarity.

Any comparison between human and animal data raises the question of homology of brain regions. Since they show analogous anatomy, comparisons of subcortical regions are not often an issue (see also [128]). In contrast, the issue of homology becomes more problematic in the case of cortical regions that show both anatomical and terminological differences between humans and animals. Nonetheless, even areas which may be 
considered largely 'higher-order' or evolutionarily more recent, such as the prefrontal cortex, may show strong structural and functional homologies between primates and other mammals, such as rodents $[129,130]$. Concerning cortical regions, we relied on criteria of homology as established by various authors [131-133]. In addition, it should be noted that due to the strict inclusion/exclusion criteria nearly all of the animal studies involve rodents with the exception of one study using monkeys [102]. As such, the generalizability to other mammals should be considered cautiously. Nonetheless, beyond the studies included here, studies involving primates were also considered in the discussion to add support to the translatability of the results (e.g.) $[53,66]$.

\section{Additional file}

Additonal file 1: Table S1A. Painful aversion-related brain activations in human studies. Table S1B. Non-painful aversion-related brain activations in human studies. Table S2A. Painful aversion-related brain activations in animal studies. Table S2B. Aversion-, non-painful, related brain activations in animal studies $[32,33,41,73,77,78,87,89,90,99-103$, $105-110,113-118,127,134-230]$

\section{Abbreviations}

ACC: anterior cingulate cortex; Amyg: amygdala; Al: anterior insula; Aud: auditory ctx; BG: basal ganglia; BNST: bed $\mathrm{n}$ of the stria terminalis; Ctx: cortex; D: dorsal; DMPFC: dorsomedial prefrontal ctx; DS: dorsal striatum; Hab: habenula; Hipp: hippocampal area; Hyp: hypothalamus; IC: inferior colliculus; IFG: inferior frontal gyrus; IL: infralimbic ctx; Ins: insula; Lat: lateral; LC: locus coeruleus; MCC: mid cingulate ctx; N: nucleus; NAc: nucleus accumbens; NTS: $n$ of the solitary tract; OFC: orbital frontal ctx; PAG: periaqueductal gray; Parahipp: parahippocampal gyrus; PBN: parabrachial n; PL: prelimbic; PFC: prefrontal ctx; SC: superior colliculus; Sens: sensory ctx; Sep: septal n; SMA: secondary motor area; SMG: supramarginal gyrus; STG: superior temporal gyrus; Thal: thalamus; VLOFC: ventrolateral orbitofrontal ctx; VTA: ventral tegmental area.

\section{Competing interests}

The authors have no competing interests to declare.

\section{Acknowledgements}

The authors would like to thank Niall W. Duncan for his assistance with the MKDA meta-analysis. In addition, we would like to thank Niall W. Duncan, Aaron Kucyi, and the reviewers for their critical reading of the manuscript. G. N. holds a Canada Research Chair for Mind, Brain imaging and Neuroethics as well as an EJLB-CIHR Michael Smith Chair in Neurosciences and Mental Health. D.J.H holds a Postdoctoral Fellowship from the Canadian Institutes of Health Research (CIHR).

\section{Authors' contributions}

DJH performed the analyses and drafted the manuscript. DJH and GN conceived of the study, and read and approved the final manuscript.

Received: 20 February 2012 Accepted: 18 April 2012

Published: 7 June 2012

\section{References}

1. Ardiel $\mathrm{EL}$, Rankin $\mathrm{CH}$ : An elegant mind: learning and memory in Caenorhabditis elegans. Learn Mem 2010, 17(4):191-201.

2. Glanzman DL: Associative learning: Hebbian flies. Curr Bio/ 2005, 15(11):R416-R419.

3. Seymour B, Singer T, Dolan R: The neurobiology of punishment. Nat Rev Neurosci 2007, 8(4):300-311.
4. Wise RA: Dopamine, learning and motivation. Nat Rev Neurosci 2004, 5(6):483-494.

5. Hayes DJ, Northoff G: Identifying a network of brain regions involved in aversion-related processing: a cross-species translational investigation. Front Integr Neurosci 2011, 5:49.

6. Apkarian AV, Bushnell MC, Treede RD, Zubieta JK: Human brain mechanisms of pain perception and regulation in health and disease. Eur J Pain 2005, 9(4):463-484.

7. Minami M: Neuronal mechanisms for pain-induced aversion behavioral studies using a conditioned place aversion test. Int Rev Neurobio/ 2009, 85:135-144.

8. Oertel BG, Preibisch C, Wallenhorst T, Hummel T, Geisslinger G, Lanfermann $\mathrm{H}$, Lotsch J: Differential opioid action on sensory and affective cerebral pain processing. Clin Pharmacol Ther 2008, 83(4):577-588.

9. Tracey I: Imaging pain. Br J Anaesth 2008, 101(1):32-39.

10. Melzack R: Pain-an overview. Acta Anaesthesio/ Scand 1999, 43(9):880-884

11. lannetti GD, Mouraux A: From the neuromatrix to the pain matrix (and back). Exp Brain Res 2010, 205(1):1-12.

12. Mouraux A, Diukova A, Lee MC, Wise RG, lannetti GD: A multisensory investigation of the functional significance of the "pain matrix". Neurolmage 2011, 54(3):2237-2249.

13. Downar J, Mikulis DJ, Davis KD: Neural correlates of the prolonged salience of painful stimulation. Neurolmage 2003, 20(3):1540-1551.

14. Giordano J, Abramson K, Boswell MV: Pain assessment: subjectivity, objectivity, and the use of neurotechnology. Pain Physician 2010, 13(4):305-315.

15. Rolls ET, Grabenhorst F, Parris BA: Warm pleasant feelings in the brain. Neurolmage 2008, 41(4):1504-1513.

16. Meriau K, Wartenburger I, Kazzer P, Prehn K, Villringer A, van der Meer E, Heekeren HR: Insular activity during passive viewing of aversive stimuli reflects individual differences in state negative affect. Brain Cogn 2009, 69(1):73-80.

17. Walker DL, Toufexis DJ, Davis M: Role of the bed nucleus of the stria terminalis versus the amygdala in fear, stress, and anxiety. Eur J Pharmacol 2003, 463(1-3):199-216.

18. Jhou T: Neural mechanisms of freezing and passive aversive behaviors. J Comp Neurol 2005, 493(1):111-114.

19. Misslin R: The defense system of fear: behavior and neurocircuitry. Neurophysiol Clin 2003, 33(2):55-66.

20. Carlezon WA Jr, Thomas MJ: Biological substrates of reward and aversion: a nucleus accumbens activity hypothesis. Neuropharmacology 2009, 56(Suppl 1):122-132

21. Wise RA: Brain reward circuitry: insights from unsensed incentives. Neuron 2002, 36(2):229-240.

22. Breiter $\mathrm{HC}$, Rosen BR: Functional magnetic resonance imaging of brain reward circuitry in the human. Ann N Y Acad Sci 1999, 877:523-547.

23. Ikemoto S: Brain reward circuitry beyond the mesolimbic dopamine system: A neurobiological theory. Neurosci Biobehav Rev 2010, 35(2):129-150.

24. Duerden EG, Albanese MC: Localization of pain-related brain activation: A meta-analysis of neuroimaging data. Hum Brain Mapp 2011. doi:10.1002/ hbm.21416 [Epub ahead of print]

25. Sandner G, Oberling P, Silveira MC, Di Scala G, Rocha B, Bagri A, Depoortere $\mathrm{R}$ : What brain structures are active during emotions? Effects of brain stimulation elicited aversion on c-fos immunoreactivity and behavior. Behav Brain Res 1993, 58(1-2):9-18.

26. Wager TD, Lindquist MA, Nichols TE, Kober H, Van Snellenberg JX: Evaluating the consistency and specificity of neuroimaging data using meta-analysis. Neurolmage 2009, 45(1 Suppl):S210-S221.

27. Devonshire IM, Papadakis NG, Port M, Berwick J, Kennerley AJ, Mayhew JE, Overton PG: Neurovascular coupling is brain region-dependent. Neurolmage 2012, 59:1997-2006.

28. Nichols T, Brett M, Andersson J, Wager T, Poline JB: Valid conjunction inference with the minimum statistic. Neurolmage 2005, 25(3):653-660.

29. Krebs RM, Heipertz D, Schuetze H, Duzel E: Novelty increases the mesolimbic functional connectivity of the substantia nigra/ventral tegmental area (SN/VTA) during reward anticipation: Evidence from high-resolution fMRI. Neurolmage 2011, 58(2):647-655.

30. Villemure C, Bushnell MC: Mood influences supraspinal pain processing separately from attention. J Neurosci 2009, 29(3):705-715.

31. Strigo IA, Duncan GH, Boivin M, Bushnell MC: Differentiation of visceral and cutaneous pain in the human brain. J Neurophysiol 2003, 89(6):3294-3303. 
32. Shih $Y Y$, Chiang YC, Chen JC, Huang CH, Chen YY, Liu RS, Chang C, Jaw FS: Brain nociceptive imaging in rats using (18)f-fluorodeoxyglucose small-animal positron emission tomography. Neuroscience 2008, 155(4):1221-1226

33. Hess A, Sergejeva M, Budinsky L, Zeilhofer HU, Brune K: Imaging of hyperalgesia in rats by functional MRI. Eur J Pain 2007, 11(1):109-119.

34. Logothetis NK: What we can do and what we cannot do with fMRI. Nature 2008, 453(7197):869-878.

35. Fairhurst M, Wiech K, Dunckley P, Tracey l: Anticipatory brainstem activity predicts neural processing of pain in humans. Pain 2007, 128(1-2):101-110.

36. Becerra L, Breiter HC, Wise R, Gonzalez RG, Borsook D: Reward circuitry activation by noxious thermal stimuli. Neuron 2001, 32(5):927-946.

37. Levita L, Hare TA, Voss HU, Glover G, Ballon DJ, Casey BJ: The bivalent side of the nucleus accumbens. Neurolmage 2009, 44(3):1178-1187.

38. Klucken T, Kagerer S, Schweckendiek J, Tabbert K, Vaitl D, Stark R: Neural, electrodermal and behavioral response patterns in contingency aware and unaware subjects during a picture-picture conditioning paradigm. Neuroscience 2009, 158(2):721-731.

39. Lim LW, Temel Y, Visser-Vandewalle V, Blokland A, Steinbusch H: Fos immunoreactivity in the rat forebrain induced by electrical stimulation of the dorsolateral periaqueductal gray matter. J Chem Neuroanat 2009, 38(2):83-96

40. Mobbs D, Petrovic P, Marchant JL, Hassabis D, Weiskopf N, Seymour B, Dolan RJ, Frith CD: When fear is near: threat imminence elicits prefrontalperiaqueductal gray shifts in humans. Science 2007, 317(5841):1079-1083.

41. Day HE, Masini CV, Campeau S: The pattern of brain c-fos mRNA induced by a component of fox odor, 2,5-dihydro-2,4,5-trimethylthiazoline (TMT), in rats, suggests both systemic and processive stress characteristics. Brain Res 2004, 1025(1-2):139-151.

42. Eisenberger NI, Gable SL, Lieberman MD: Functional magnetic resonance imaging responses relate to differences in real-world social experience. Emotion 2007, 7(4):745-754

43. Nikulina EM, Arrillaga-Romany I, Miczek KA, Hammer RP Jr: Long-lasting alteration in mesocorticolimbic structures after repeated social defeat stress in rats: time course of mu-opioid receptor mRNA and FosB/ DeltaFosB immunoreactivity. Eur J Neurosci 2008, 27(9):2272-2284.

44. Talbot JD, Marrett S, Evans AC, Meyer E, Bushnell MC, Duncan GH: Multiple representations of pain in human cerebral cortex. Science 1991, 251(4999):1355-1358.

45. Jones A: The pain matrix and neuropathic pain. Brain 1998, 121(Pt 5):783-784

46. Derbyshire SW, Jones AK, Gyulai F, Clark S, Townsend D, Firestone LL: Pain processing during three levels of noxious stimulation produces differential patterns of central activity. Pain 1997, 73(3):431-445.

47. Rainville P: Brain mechanisms of pain affect and pain modulation. Curr Opin Neurobiol 2002, 12(2):195-204.

48. Moulton EA, Elman I, Pendse G, Schmahmann J, Becerra L, Borsook D: Aversion-related circuitry in the cerebellum: responses to noxious heat and unpleasant images. J Neurosci 2011, 31(10):3795-3804.

49. Bellebaum C, Daum I: Mechanisms of cerebellar involvement in associative learning. Cortex 2011, 47(1):128-136.

50. Mediavilla C, Molina F, Puerto A: Retention of concurrent taste aversion learning after electrolytic lesioning of the interpositus-dentate region of the cerebellum. Brain Res 2000, 868(2):329-337.

51. Simons RF: The way of our errors: theme and variations. Psychophysiology 2010, 47(1):1-14.

52. Bossaerts P: Risk and risk prediction error signals in anterior insula. Brain Struct Funct 2010, 214(5-6):645-653.

53. Haber SN, Knutson B: The reward circuit: linking primate anatomy and human imaging. Neuropsychopharmacology 2010, 35(1):4-26.

54. Wittmann M, Lovero KL, Lane SD, Paulus MP: Now or later? Striatum and insula activation to immediate versus delayed rewards. J Neurosci Psychol Econ 2010, 3(1):15-26.

55. Walton ME, Croxson PL, Behrens TE, Kennerley SW, Rushworth MF: Adaptive decision making and value in the anterior cingulate cortex. Neurolmage 2007, 36(Suppl 2):T142-T154.

56. Wiech K, Lin CS, Brodersen KH, Bingel U, Ploner M, Tracey I: Anterior insula integrates information about salience into perceptual decisions about pain. J Neurosci 2010, 30(48):16324-16331.
57. Shackman AJ, Salomons TV, Slagter HA, Fox AS, Winter JJ, Davidson RJ: The integration of negative affect, pain and cognitive control in the cingulate cortex. Nat Rev Neurosci 2011, 12(3):154-167.

58. Alexander WH, Brown JW: Medial prefrontal cortex as an action-outcome predictor. Nat Neurosci 2011, 14(10):1338-1344.

59. Kurth F, Zilles K, Fox PT, Laird AR, Eickhoff SB: A link between the systems: functional differentiation and integration within the human insula revealed by meta-analysis. Brain Struct Funct 2010, 214(5-6):519-534.

60. Maddock RJ: The retrosplenial cortex and emotion: new insights from functional neuroimaging of the human brain. Trends Neurosci 1999, 22(7):310-316

61. Small DM, Zatorre RJ, Dagher A, Evans AC, Jones-Gotman M: Changes in brain activity related to eating chocolate: from pleasure to aversion. Brain 2001, 124(Pt 9):1720-1733.

62. Sawamoto N, Honda M, Okada T, Hanakawa T, Kanda M, Fukuyama H, Konishi J, Shibasaki $\mathrm{H}$ : Expectation of pain enhances responses to nonpainful somatosensory stimulation in the anterior cingulate cortex and parietal operculum/posterior insula: an event-related functional magnetic resonance imaging study. J Neurosci 2000, 20(19):7438-7445.

63. Atlas LY, Bolger N, Lindquist MA, Wager TD: Brain mediators of predictive cue effects on perceived pain. J Neurosci 2010, 30(39):12964-12977.

64. Taylor KS, Seminowicz DA, Davis KD: Two systems of resting state connectivity between the insula and cingulate cortex. Hum Brain Mapp 2009, 30(9):2731-2745.

65. Sagaspe $P$, Schwartz $S$, Vuilleumier P: Fear and stop: a role for the amygdala in motor inhibition by emotional signals. Neurolmage 2011, 55(4):1825-1835.

66. Schultz W, Tremblay L, Hollerman JR: Reward processing in primate orbitofrontal cortex and basal ganglia. Cereb Cortex 2000, 10(3):272-284.

67. Sharot T, Shiner T, Dolan RJ: Experience and choice shape expected aversive outcomes. J Neurosci 2010, 30(27):9209-9215.

68. Sanders KH, Klein CE, Mayor TE, Heym C, Handwerker HO: Differential effects of noxious and non-noxious input on neurones according to location in ventral periaqueductal grey or dorsal raphe nucleus. Brain Res 1980, 186(1):83-97.

69. Schenberg LC, Povoa RM, Costa AL, Caldellas AV, Tufik S, Bittencourt AS: Functional specializations within the tectum defense systems of the rat. Neurosci Biobehav Rev 2005, 29(8):1279-1298.

70. Hadjipavlou G, Dunckley P, Behrens TE, Tracey I: Determining anatomical connectivities between cortical and brainstem pain processing regions in humans: a diffusion tensor imaging study in healthy controls. Pain 2006, 123(1-2):169-178.

71. Linnman C, Moulton EA, Barmettler G, Becerra L, Borsook D: Neuroimaging of the periaqueductal gray: state of the field. Neurolmage 2012, 60(1):505-522.

72. Critchley HD, Wiens S, Rotshtein P, Ohman A, Dolan RJ: Neural systems supporting interoceptive awareness. Nat Neurosci 2004, 7(2):189-195.

73. Wang Z, Guo Y, Bradesi S, Labus JS, Maarek JM, Lee K, Winchester WJ, Mayer EA, Holschneider DP: Sex differences in functional brain activation during noxious visceral stimulation in rats. Pain 2009, 145(1-2):120-128.

74. Menon V, Uddin LQ: Saliency, switching, attention and control: a network model of insula function. Brain Struct Funct 2010, 214(5-6):655-667.

75. Hayes DJ, Huxtable AG: Interpreting deactivations in neuroimaging. Front Psychol 2012, 3:27.

76. Northoff G, Duncan NW, Hayes DJ: The brain and its resting state activityexperimental and methodological implications. Prog Neurobiol 2010, 92(4):593-600.

77. Inui-Yamamoto C, Yoshioka Y, Inui T, Sasaki KS, Ooi Y, Ueda K, Seiyama A, Ohzawa l: The brain mapping of the retrieval of conditioned taste aversion memory using manganese-enhanced magnetic resonance imaging in rats. Neuroscience 2010, 167(2):199-204.

78. Shih YY, Chen YY, Chen CC, Chen JC, Chang C, Jaw FS: Whole-brain functional magnetic resonance imaging mapping of acute nociceptive responses induced by formalin in rats using atlas registration-based event-related analysis. J Neurosci Res 2008, 86(8):1801-1811.

79. Wiebking C, de Greck M, Duncan NW, Heinzel A, Tempelmann C, Northoff $\mathrm{G}$ : Are emotions associated with activity during rest or interoception? An exploratory fMRI study in healthy subjects. Neurosci Lett 2011, 491(1):87-92.

80. Liu X, Hairston J, Schrier M, Fan J: Common and distinct networks underlying reward valence and processing stages: a meta-analysis of 
functional neuroimaging studies. Neurosci Biobehav Rev 2011, 35(5):1219-1236.

81. Hayes DJ, Hoang J, Greenshaw AJ: The role of nucleus accumbens shell GABA receptors on ventral tegmental area intracranial self-stimulation and a potential role for the 5-HT2C receptor. J Psychopharmacol 2011, 25(12):1661-1675.

82. Leknes S, Tracey I: A common neurobiology for pain and pleasure. Nat Rev Neurosci 2008, 9(4):314-320.

83. Lammel S, Ion DI, Roeper J, Malenka RC: Projection-specific modulation of dopamine neuron synapses by aversive and rewarding stimuli. Neuron 2011, 70(5):855-862.

84. Hikida T, Kimura K, Wada N, Funabiki K, Nakanishi S: Distinct roles of synaptic transmission in direct and indirect striatal pathways to reward and aversive behavior. Neuron 2010, 66(6):896-907.

85. Kawasaki H, Adolphs R, Oya H, Kovach C, Damasio H, Kaufman O, Howard M 3rd: Analysis of single-unit responses to emotional scenes in human ventromedial prefrontal cortex. J Cogn Neurosci 2005. 17(10):1509-1518.

86. Madan CR, Spetch ML: Is the enhancement of memory due to reward driven by value or salience? Acta Psychol (Amst) 2012, 139(2):343-349.

87. Nakagawa T, Katsuya A, Tanimoto S, Yamamoto J, Yamauchi Y, Minami M, Satoh M: Differential patterns of c-fos mRNA expression in the amygdaloid nuclei induced by chemical somatic and visceral noxious stimuli in rats. Neurosci Lett 2003, 344(3):197-200.

88. Rottschy C, Langner R, Dogan I, Reetz K, Laird AR, Schulz JB, Fox PT, Eickhoff SB: Modelling neural correlates of working memory: A coordinate-based meta-analysis. Neurolmage 2011, 60(1):830-846.

89. Calandreau $L$, Jaffard $R$, Desmedt A: Dissociated roles for the lateral and medial septum in elemental and contextual fear conditioning. Learn Mem 2007, 14(6):422-429.

90. Yasoshima Y, Scott TR, Yamamoto T: Differential activation of anterior and midline thalamic nuclei following retrieval of aversively motivated learning tasks. Neuroscience 2007, 146(3):922-930.

91. Straube T, Weiss T, Mentzel HJ, Miltner WH: Time course of amygdala activation during aversive conditioning depends on attention. Neurolmage 2007, 34(1):462-469.

92. Marschner A, Kalisch R, Vervliet B, Vansteenwegen D, Buchel C: Dissociable roles for the hippocampus and the amygdala in human cued versus context fear conditioning. J Neurosci 2008, 28(36):9030-9036.

93. Strigo IA, Simmons AN, Matthews SC, Craig AD: The relationship between amygdala activation and passive exposure time to an aversive cue during a continuous performance task. PLoS One 2010, 5(11):e15093.

94. Ziv M, Tomer R, Defrin R, Hendler T: Individual sensitivity to pain expectancy is related to differential activation of the hippocampus and amygdala. Hum Brain Mapp 2010, 31(2):326-338.

95. Dube AA, Duquette M, Roy M, Lepore F, Duncan G, Rainville P: Brain activity associated with the electrodermal reactivity to acute heat pain. Neurolmage 2009, 45(1):169-180.

96. Guimarais M, Gregorio A, Cruz A, Guyon N, Moita MA: Time determines the neural circuit underlying associative fear learning. Front Behav Neurosci 2011, 5:89.

97. Herwig U, Abler B, Walter H, Erk S: Expecting unpleasant stimuli-an fMRI study. Psychiatry Res 2007, 154(1):1-12.

98. Jensen J, McIntosh AR, Crawley AP, Mikulis DJ, Remington G, Kapur S: Direct activation of the ventral striatum in anticipation of aversive stimuli. Neuron 2003, 40(6):1251-1257.

99. Radwanska K, Nikolaev E, Knapska E, Kaczmarek L: Differential response of two subdivisions of lateral amygdala to aversive conditioning as revealed by c-Fos and P-ERK mapping. NeuroReport 2002 13(17):2241-2246

100. Badowska-Szalewska E, Ludkiewicz B, Domaradzka-Pytel B, Dziewiatkowski J, Spodnik JH, Morys J: The immunoreactivity of c-Fos, NGF and its receptor TrkA after open-field exposure in the central and medial nuclei of the rat amygdala. Folia Morphol (Warsz) 2006, 65(2):145-151.

101. Calfa G, Bussolino D, Molina VA: Involvement of the lateral septum and the ventral Hippocampus in the emotional sequelae induced by social defeat: role of glucocorticoid receptors. Behav Brain Res 2007, 181(1):23-34.

102. Hoffman KL, Gothard KM, Schmid MC, Logothetis NK: Facial-expression and gaze-selective responses in the monkey amygdala. Curr Biol 2007 17(9):766-772.
103. Mediavilla C, Bernal A, Puerto A: Taste aversion learning induced c-fos expression in the nucleus of the solitary tract after spontaneous flavor intake: role of the inter-stimulus interval. Neurobiol Learn Mem 2007, 88(2):264-268.

104. Baumgartel K, Genoux D, Welzl H, Tweedie-Cullen RY, Koshibu K, Livingstone-Zatchej M, Mamie C, Mansuy IM: Control of the establishment of aversive memory by calcineurin and Zif268. Nat Neurosci 2008, 11(5):572-578.

105. Kwon B, Goltz M, Houpt TA: Expression of AP-1 family transcription factors in the amygdala during conditioned taste aversion learning: role for Fra-2. Brain Res 2008, 1207:128-141.

106. Butler RK, Sharko AC, Oliver EM, Brito-Vargas P, Kaigler KF, Fadel JR, Wilson MA: Activation of phenotypically-distinct neuronal subpopulations of the rat amygdala following exposure to predator odor. Neuroscience 2011, 175:133-144.

107. Culman J, Das G, Ohlendorf C, Haass M, Maser-Gluth C, Zuhayra M, Zhao Y, Itoi K: Blockade of tachykinin NK1/NK2 receptors in the brain attenuates the activation of corticotrophin-releasing hormone neurones in the hypothalamic paraventricular nucleus and the sympathoadrenal and pituitary-adrenal responses to formalin-induced pain in the rat J Neuroendocrinol 2010, 22(5):467-476.

108. Hagiwara H, Kimura F, Mitsushima D, Funabashi T: Formalin-induced nociceptive behavior and c-Fos expression in middle-aged female rats. Physiol Behav 2010, 100(2):101-104.

109. Vrang N, Phifer CB, Corkern MM, Berthoud HR: Gastric distension induces c-Fos in medullary GLP-1/2-containing neurons. Am J Physiol Regul Integr Comp Physiol 2003, 285(2):R470-R478.

110. Shih YY, Chen CC, Shyu BC, Lin ZJ, Chiang YC, Jaw FS, Chen YY, Chang C: A new scenario for negative functional magnetic resonance imaging signals: endogenous neurotransmission. J Neurosci 2009, 29(10):3036-3044.

111. Edelsbrunner ME, Nakano M, Holzer P: Afferent signalling from the acidchallenged rat stomach is inhibited and gastric acid elimination is enhanced by lafutidine. BMC Gastroenterol 2009, 9:40.

112. Ren $Y$, Zhang $L, L u Y$, Yang $H$, Westlund $K N$ : Central lateral thalamic neurons receive noxious visceral mechanical and chemical input in rats. J Neurophysiol 2009, 102(1):244-258.

113. Hayashi T, Miyata M, Nagata T, Izawa Y, Kawakami Y: Intracerebroventricular fluvoxamine administration inhibited pain behavior but increased Fos expression in affective pain pathways. Pharmacol Biochem Behav 2009, 91(3):441-446.

114. Novikova NS, Kazakova TB, Rogers V, Korneva EA: Expression of the c-Fos gene in the rat hypothalamus in electrical pain stimulation and UHF stimulation of the skin. Neurosci Behav Physiol 2008, 38(4):415-420.

115. Morano TJ, Bailey NJ, Cahill CM, Dumont EC: Nuclei-and condition-specific responses to pain in the bed nucleus of the stria terminalis. Prog Neuropsychopharmacol Biol Psychiatry 2008, 32(3):643-650.

116. Gavrilov YV, Perekrest SV, Novikova NS: Intracellular expression of c-Fos protein in various structures of the hypothalamus in electrical pain stimulation and administration of antigens. Neurosci Behav Physiol 2008, 38(1):87-92

117. Li L, Ding J, Ren Z, Han Q, Hu G, Xiao M: Expression and colocalization of NADPH-diaphorase and Fos in the subnuclei of the parabrachial nucleus in rats following visceral noxious stimulation. Brain Res 2006, 1114(1):41-52.

118. Coizet V, Dommett EJ, Redgrave P, Overton PG: Nociceptive responses of midbrain dopaminergic neurones are modulated by the superior colliculus in the rat. Neuroscience 2006, 139(4):1479-1493.

119. Costafreda SG, Brammer MJ, David AS, Fu CH: Predictors of amygdala activation during the processing of emotional stimuli: a meta-analysis of 385 PET and fMRI studies. Brain Res Rev 2008, 58(1):57-70.

120. Mechias ML, Etkin A, Kalisch R: A meta-analysis of instructed fear studies: implications for conscious appraisal of threat. Neurolmage 2010, 49(2):1760-1768.

121. Fan $Y$, Duncan NW, de Greck M, Northoff G: Is there a core neural network in empathy? An fMRI based quantitative meta-analysis. Neurosci Biobehav Rev 2011, 35(3):903-911.

122. Kober H, Barrett LF, Joseph J, Bliss-Moreau E, Lindquist K, Wager TD: Functional grouping and cortical-subcortical interactions in emotion: a meta-analysis of neuroimaging studies. Neurolmage 2008, 42(2):998-1031.

123. Delgado MR, Jou RL, Phelps EA: Neural systems underlying aversive conditioning in humans with primary and secondary reinforcers. Front Neurosci 2011, 5:71 
124. Johnson LR, Hou M, Prager EM, Ledoux JE: Regulation of the Fear Network by Mediators of Stress: Norepinephrine Alters the Balance between Cortical and Subcortical Afferent Excitation of the Lateral Amygdala. Front Behav Neurosci 2011, 5:23.

125. Vogt BA: Pain and emotion interactions in subregions of the cingulate gyrus. Nat Rev Neurosci 2005, 6(7):533-544

126. Salimi-Khorshidi G, Smith SM, Keltner JR, Wager TD, Nichols TE: Metaanalysis of neuroimaging data: a comparison of image-based and coordinate-based pooling of studies. Neurolmage 2009, 45(3):810-823.

127. Salchner P, Sartori SB, Sinner C, Wigger A, Frank E, Landgraf R, Singewald N: Airjet and FG-7142-induced Fos expression differs in rats selectively bred for high and low anxiety-related behavior. Neuropharmacology 2006, 50(8):1048-1058

128. Panksepp J: Affectvie neuroscience: the foundations of human and animal emotions. New York: Oxford University Press; 1998.

129. Dalley JW, Cardinal RN, Robbins TW: Prefrontal executive and cognitive functions in rodents: neural and neurochemical substrates. Neurosci Biobehav Rev 2004, 28(7):771-784

130. Heidbreder CA, Groenewegen HJ: The medial prefrontal cortex in the rat: evidence for a dorso-ventral distinction based upon functional and anatomical characteristics. Neurosci Biobehav Rev 2003, 27(6):555-579.

131. Ongur D, Price $J$ : The organization of networks within the orbital and medial prefrontal cortex of rats, monkeys and humans. Cereb Cortex 2000, 10(3):206-219.

132. Shumake J, Gonzalez-Lima F: Brain systems underlying susceptibility to helplessness and depression. Behav Cogn Neurosci Rev 2003, 2(3):198-221.

133. Vertes RP: Interactions among the medial prefrontal cortex, hippocampus and midline thalamus in emotional and cognitive processing in the rat. Neuroscience 2006, 142(1):1-20

134. Albrechet-Souza L, Borelli KG, Carvalho MC, Brandao ML: The anterior cingulate cortex is a target structure for the anxiolytic-like effects of benzodiazepines assessed by repeated exposure to the elevated plus maze and Fos immunoreactivity. Neuroscience 2009, 164:387-397.

135. Baffi JS, Palkovits M: Fine topography of brain areas activated by cold stress. A fos immunohistochemical study in rats. Neuroendocrinology 2000, 72:102-113.

136. Bernstein IL, Koh MT: Molecular signaling during taste aversion learning. Chem Senses 2007, 32:99-103

137. Chang C, Shyu BC: A fMRI study of brain activations during non-noxious and noxious electrical stimulation of the sciatic nerve of rats. Brain Res 2001, 897:71-81.

138. Chen W, Tenney J, Kulkarni P, King JA: Imaging unconditioned fear response with manganese-enhanced MRI (MEMRI). Neuroimage 2007, 37:221-229.

139. Dardou D, Datiche F, Cattarelli M: Fos and Egr1 expression in the rat brain in response to olfactory cue after taste-potentiated odor aversion retrieval. Learn Mem 2006, 13:150-160.

140. Dardou D, Datiche F, Cattarelli M: Does taste or odor activate the same brain networks after retrieval of taste potentiated odor aversion? Neurobiol Learn Mem 2007, 88:186-197.

141. Dielenberg RA, Hunt GE, McGregor IS: "When a rat smells a cat": the distribution of Fos immunoreactivity in rat brain following exposure to a predatory odor. Neuroscience 2001, 104:1085-1097.

142. Fekete EM, Zhao Y, Li C, Sabino V, Vale WW, Zorrilla EP: Social defeat stress activates medial amygdala cells that express type 2 corticotropinreleasing factor receptor mRNA. Neuroscience 2009, 162:5-13.

143. Ferreira G, Ferry B, Meurisse M, Levy F: Forebrain structures specifically activated by conditioned taste aversion. Behav Neurosci 2006, 120:952-962.

144. Funk D, Amir S: Enhanced fos expression within the primary olfactory and limbic pathways induced by an aversive conditioned odor stimulus. Neuroscience 2000, 98:403-406.

145. Furlong TM, Cole S, Hamlin AS, McNally GP: The role of prefrontal cortex in predictive fear learning. Behav Neurosci 2010, 124:574-586.

146. Garcia-Medina NE, Jimenez-Capdeville ME, Ciucci M, Martinez LM, Delgado JM, Horn CC: Conditioned flavor aversion and brain Fos expression following exposure to arsenic. Toxicology 2007, 235:73-82.

147. Hao S, Dulake M, Espero E, Sternini C, Raybould HE, Rinaman L: Central Fos expression and conditioned flavor avoidance in rats following intragastric administration of bitter taste receptor ligands. Am J Physiol Regul Integr Comp Physiol 2009, 296:R528-R536.
148. Jhou TC, Fields HL, Baxter MG, Saper CB, Holland PC: The rostromedial tegmental nucleus (RMTg), a GABAergic afferent to midbrain dopamine neurons, encodes aversive stimuli and inhibits motor responses. Neuron 2009, 61:786-800.

149. Johnson PL, Fitz SD, Hollis JH, Moratalla R, Lightman SL, Shekhar A, Lowry CA: Induction of c-Fos in 'panic/defence'-related brain circuits following brief hypercarbic gas exposure. J Psychopharmacol 2010a.

150. Johnson ZV, Revis AA, Burdick MA, Rhodes JS: A similar pattern of neuronal Fos activation in 10 brain regions following exposure to reward- or aversion-associated contextual cues in mice. Physiol Behav 2010, 99:412-418.

151. Koh MT, Bernstein IL: Mapping conditioned taste aversion associations using c-Fos reveals a dynamic role for insular cortex. Behav Neurosci 2005, 119:388-398.

152. Lamprea MR, Cardenas FP, Vianna DM, Castilho VM, Cruz-Morales SE, Brandao ML: The distribution of fos immunoreactivity in rat brain following freezing and escape responses elicited by electrical stimulation of the inferior colliculus. Brain Res 2002, 950:186-194.

153. Lehner M, Taracha E, Skorzewska A, Turzynska D, Sobolewska A, Maciejak P, Szyndler J, Hamed A, Bidzinski A, Wislowska-Stanek A, Plaznik A: Expression of c-Fos and CRF in the brains of rats differing in the strength of a fear response. Behav Brain Res 2008, 188:154-167.

154. Lehner M, Taracha E, Skorzewska A, Wislowska A, Zienowicz M, Maciejak P, Szyndler J, Bidzinski A, Plaznik A: Sensitivity to pain and c-Fos expression in brain structures in rats. Neurosci Lett 2004, 370:74-79.

155. Lei LG, Zhang YQ, Zhao ZQ: Pain-related aversion and Fos expression in the central nervous system in rats. Neuroreport 2004, 15:67-71.

156. Lemos Jl, Resstel LB, Guimaraes FS: Involvement of the prelimbic prefrontal cortex on cannabidiol-induced attenuation of contextual conditioned fear in rats. Behav Brain Res 2010, 207:105-111.

157. Lowe AS, Beech JS, Williams SC: Small animal, whole brain fMRI: innocuous and nociceptive forepaw stimulation. Neuroimage 2007, 35:719-728.

158. Malisza KL, Docherty JC: Capsaicin as a source for painful stimulation in functional MRI. J Magn Reson Imaging 2001, 14:341-347.

159. Malisza KL, Gregorash L, Turner A, Foniok T, Stroman PW, Allman AA Summers $R$, Wright A: Functional MRI involving painful stimulation of the ankle and the effect of physiotherapy joint mobilization. Magn Reson Imaging 2003, 21:489-496.

160. Malkani S, Rosen JB: Induction of NGFI-B mRNA following contextual fear conditioning and its blockade by diazepam. Brain Res Mol Brain Res 2000 80:153-165.

161. Martinez RC, Carvalho-Netto EF, Ribeiro-Barbosa ER, Baldo MV, Canteras NS: Amygdalar roles during exposure to a live predator and to a predatorassociated context. Neuroscience 2011, 172:314-328.

162. Martinez V, Wang L, Tache $Y$ : Proximal colon distension induces Fos expression in the brain and inhibits gastric emptying through capsaicinsensitive pathways in conscious rats. Brain Res 2006, 1086:168-180.

163. Mickley GA, Kenmuir CL, McMullen CA, Yocom AM, Valentine EL, DenglerCrish CM, Weber B, Wellman JA, Remmers-Roeber DR: Dynamic processing of taste aversion extinction in the brain. Brain Res 2004, 1016:79-89.

164. Moylan Governo RJ, Morris PG, Prior MJ, Marsden CA, Chapman V: Capsaicin-evoked brain activation and central sensitization in anaesthetised rats: a functional magnetic resonance imaging study. Pain 2006, 126:35-45.

165. Navarro M, Spray KJ, Cubero I, Thiele TE, Bernstein IL: cFos induction during conditioned taste aversion expression varies with aversion strength. Brain Res 2000, 887:450-453.

166. Nikolaev E, Kaczmarek L, Zhu SW, Winblad B, Mohammed AH: Environmental manipulation differentially alters c-Fos expression in amygdaloid nuclei following aversive conditioning. Brain Res 2002, 957:91-98.

167. Roche M, Johnston P, Mhuircheartaigh ON, Olango WM, Mackie K, Finn DP: Eur J Pain 2009.

168. Roseboom PH, Nanda SA, Bakshi VP, Trentani A, Newman SM, Kalin NH: Predator threat induces behavioral inhibition, pituitary-adrenal activation and changes in amygdala CRF-binding protein gene expression. Psychoneuroendocrinology 2007, 32:44-55.

169. Sadananda M, Wohr M, Schwarting RK: Playback of $22-\mathrm{kHz}$ and $50-\mathrm{kHz}$ ultrasonic vocalizations induces differential c-fos expression in rat brain. Neurosci Lett 2008, 435:17-23. 
170. Shah YB, Haynes L, Prior MJ, Marsden CA, Morris PG, Chapman V: Functional magnetic resonance imaging studies of opioid receptormediated modulation of noxious-evoked BOLD contrast in rats. Psychopharmacology (Berl) 2005, 180:761-773.

171. Shih YY, Chang C, Chen JC, Jaw FS: BOLD fMRI mapping of brain responses to nociceptive stimuli in rats under ketamine anesthesia. Med Eng Phys 2008, 30:953-958.

172. Shih YY, Chen YY, Chen JM, Lung Y, Chen JY, Chang C, Chen JC, Jaw FS: Exploring nociceptive response by BOLD $\mathrm{FMRI}$ in alpha-chloralose anesthetized rats. Conf Proc IEEE Eng Med Biol Soc 2006, 1:33-36.

173. Shih YY, Wey HY, De La Garza BH, Duong TQ: Striatal and cortical BOLD, blood flow, blood volume, oxygen consumption, and glucose consumption changes in noxious forepaw electrical stimulation. J Cereb Blood Flow Metab 2011, 31:832-841

174. Sinniger $V$, Porcher $C$, Mouchet $P$, Juhem A, Bonaz B: c-fos and CRF receptor gene transcription in the brain of acetic acid-induced somatovisceral pain in rats. Pain 2004, 110:738-750.

175. St Andre J, Albanos K, Reilly S: C-fos expression in the rat brain following lithium chloride-induced illness. Brain Res 2007, 1135:122-128.

176. Tuor UI, Malisza K, Foniok T, Papadimitropoulos R, Jarmasz M, Somorjai R, Kozlowski P: Functional magnetic resonance imaging in rats subjected to intense electrical and noxious chemical stimulation of the forepaw. Pain 2000, 87:315-324.

177. Vianna DM, Borelli KG, Ferreira-Netto C, Macedo CE, Brandao ML: Fos-like immunoreactive neurons following electrical stimulation of the dorsal periaqueductal gray at freezing and escape thresholds. Brain Res Bull 2003, 62:179-189.

178. Wang L, Martinez V, Larauche $M$, Tache Y: Proximal colon distension induces Fos expression in oxytocin-, vasopressin-, CRF- and catecholamines-containing neurons in rat brain. Brain Res 2009, 1247:79-91.

179. Wilkins EE, Bernstein IL: Conditioning method determines patterns of cfos expression following novel taste-illness pairing. Behav Brain Res 2006 169:93-97.

180. Yasoshima Y, Scott TR, Yamamoto T: Memory-dependent c-Fos expression in the nucleus accumbens and extended amygdala following the expression of a conditioned taste aversive in the rat. Neuroscience 2006, 141:35-45.

181. Yu O, Parizel N, Pain L, Guignard B, Eclancher B, Mauss Y, Grucker D: Texture analysis of brain MRI evidences the amygdala activation by nociceptive stimuli under deep anesthesia in the propofol-formalin rat model. Magn Reson Imaging 2007, 25:144-146.

182. Zanoveli JM, Ferreira-Netto C, Brandao ML: Conditioned place aversion organized in the dorsal periaqueductal gray recruits the laterodorsal nucleus of the thalamus and the basolateral amygdala. Exp Neurol 2007, 208:127-136.

183. Apkarian AV, Gelnar PA, Krauss BR, Szeverenyi NM: Cortical responses to thermal pain depend on stimulus size: a functional MRI study. J Neurophysiol 2000, 83:3113-3122.

184. Becerra L, ladarola M, Borsook D: CNS activation by noxious heat to the hand or foot: site-dependent delay in sensory but not emotion circuitry. J Neurophysiol 2004, 91:533-541.

185. Casey KL, Morrow TJ, Lorenz J, Minoshima S: Temporal and spatial dynamics of human forebrain activity during heat pain: analysis by positron emission tomography. J Neurophysiol 2001, 85:951-959.

186. Coghill RC, Sang CN, Maisog JM, ladarola MJ: Pain intensity processing within the human brain: a bilateral, distributed mechanism. J Neurophysiol 1999, 82:1934-1943.

187. Derbyshire SW, Jones AK, Creed F, Starz T, Meltzer CC, Townsend DW, Peterson AM, Firestone L: Cerebral responses to noxious thermal stimulation in chronic low back pain patients and normal controls. Neuroimage 2002, 16:158-168.

188. Derbyshire SW, Whalley MG, Stenger VA, Oakley DA: Cerebral activation during hypnotically induced and imagined pain. Neuroimage 2004, 23:392-401.

189. Dimitrova A, Kolb FP, Elles HG, Maschke M, Gerwig M, Gizewski E, Timmann D: Cerebellar activation during leg withdrawal reflex conditioning: an fMRI study. Clin Neurophysiol 2004, 115:849-857.

190. Gelnar PA, Krauss BR, Sheehe PR, Szeverenyi NM, Apkarian AV: A comparative $\mathrm{FMRI}$ study of cortical representations for thermal painful, vibrotactile, and motor performance tasks. Neuroimage 1999, 10:460-482.
191. Helmchen C, Mohr C, Erdmann C, Petersen D, Nitschke MF: Differential cerebellar activation related to perceived pain intensity during noxious thermal stimulation in humans: a functional magnetic resonance imaging study. Neurosci Lett 2003, 335:202-206.

192. Hofbauer RK, Rainville P, Duncan GH, Bushnell MC: Cortical representation of the sensory dimension of pain. J Neurophysio/ 2001, 86:402-411.

193. Kurata J, Thulborn KR, Gyulai FE, Firestone LL: Early decay of pain-related cerebral activation in functional magnetic resonance imaging: comparison with visual and motor tasks. Anesthesiology 2002, 96:35-44.

194. Mohr C, Leyendecker S, Mangels I, Machner B, Sander T, Helmchen C: Central representation of cold-evoked pain relief in capsaicin induced pain: an event-related fMRI study. Pain 2009, 139:416-430

195. Morrison I, Lloyd D, di Pellegrino G, Roberts N: Vicarious responses to pain in anterior cingulate cortex: is empathy a multisensory issue? Cogn Affect Behav Neurosci 2004, 4:270-278.

196. Niddam DM, Yeh TC, Wu YT, Lee PL, Ho LT, Arendt-Nielsen L, Chen AC, Hsieh JC: Event-related functional MRI study on central representation of acute muscle pain induced by electrical stimulation. Neuroimage 2002, 17:1437-1450.

197. Ochsner KN, Ludlow DH, Knierim K, Hanelin J, Ramachandran T, Glover GC, Mackey SC: Neural correlates of individual differences in pain-related fear and anxiety. Pain 2006, 120:69-77.

198. Petrovic P, Carlsson K, Petersson KM, Hansson P, Ingvar M: Contextdependent deactivation of the amygdala during pain. J Cogn Neurosci 2004, 16:1289-1301.

199. Peyron R, Garcia-Larrea L, Gregoire MC, Costes N, Convers P, Lavenne F, Mauguiere F, Michel D, Laurent B: Haemodynamic brain responses to acute pain in humans: sensory and attentional networks. Brain 1999 122(Pt 9):1765-1780.

200. Rolls ET, Kringelbach ML, de Araujo IE: Different representations of pleasant and unpleasant odours in the human brain. Eur J Neurosci 2003, 18:695-703

201. Scott DJ, Heitzeg MM, Koeppe RA, Stohler CS, Zubieta JK: Variations in the human pain stress experience mediated by ventral and dorsal basal ganglia dopamine activity. J Neurosci 2006, 26:10789-10795.

202. Smith KA, Ploghaus A, Cowen PJ, McCleery JM, Goodwin GM, Smith S, Tracey I, Matthews PM: Cerebellar responses during anticipation of noxious stimuli in subjects recovered from depression. Functional magnetic resonance imaging study. Br J Psychiatry 2002, 181:411-415.

203. Tolle TR, Kaufmann T, Siessmeier T, Lautenbacher S, Berthele A, Munz F, Zieglgansberger W, Willoch F, Schwaiger M, Conrad B, Bartenstein P: Region-specific encoding of sensory and affective components of pain in the human brain: a positron emission tomography correlation analysis. Ann Neurol 1999, 45:40-47.

204. Abler B, Erk S, Herwig U, Walter H: Anticipation of aversive stimuli activates extended amygdala in unipolar depression. J Psychiatr Res 2007, 41:511-522

205. Blood AJ, Zatorre RJ, Bermudez P, Evans AC: Emotional responses to pleasant and unpleasant music correlate with activity in paralimbic brain regions. Nat Neurosci 1999, 2:382-387.

206. Botvinick M, Jha AP, Bylsma LM, Fabian SA, Solomon PE, Prkachin KM: Viewing facial expressions of pain engages cortical areas involved in the direct experience of pain. Neuroimage 2005, 25:312-319.

207. Buchel C, Bornhovd K, Quante M, Glauche V, Bromm B, Weiller C: Dissociable neural responses related to pain intensity, stimulus intensity, and stimulus awareness within the anterior cingulate cortex: a parametric single-trial laser functional magnetic resonance imaging study. J Neurosci 2002, 22:970-976.

208. Buchel C, Dolan RJ, Armony JL, Friston KJ: Amygdala-hippocampal involvement in human aversive trace conditioning revealed through event-related functional magnetic resonance imaging. J Neurosci 1999 19:10869-10876.

209. Frings M, Maschke M, Erichsen M, Jentzen W, Muller SP, Kolb FP, Diener HC, Timmann D: Involvement of the human cerebellum in fear-conditioned potentiation of the acoustic startle response: a PET study. Neuroreport 2002, 13:1275-1278.

210. Garrett AS, Maddock RJ: Separating subjective emotion from the perception of emotion-inducing stimuli: an fMRI study. Neuroimage 2006, 33:263-274. 
211. Gottfried JA, O'doherty J, Dolan RJ: Appetitive and aversive olfactory learning in humans studied using event-related functional magnetic resonance imaging. J Neurosci 2002, 22:10829-10837.

212. Grabenhorst F, Rolls ET, Margot C, Da Silva MA, Velazco MI: How pleasant and unpleasant stimuli combine in different brain regions: odor mixtures. J Neurosci 2007, 27:13532-13540.

213. Hamann S, Mao H: Positive and negative emotional verbal stimuli elicit activity in the left amygdala. Neuroreport 2002, 13:15-19.

214. Hamann SB, Ely TD, Hoffman JM, Kilts CD: Ecstasy and agony: activation of the human amygdala in positive and negative emotion. Psychol Sci 2002, 13:135-141.

215. Herpertz SC, Dietrich TM, Wenning B, Krings T, Erberich SG, Willmes K, Thron A, Sass $\mathrm{H}$ : Evidence of abnormal amygdala functioning in borderline personality disorder: a functional MRI study. Biol Psychiatry 2001, 50:292-298.

216. Liberzon I, Phan KL, Decker LR, Taylor SF: Extended amygdala and emotional salience: a PET activation study of positive and negative affect. Neuropsychopharmacology 2003, 28:726-733.

217. Liberzon I, Taylor SF, Fig LM, Decker LR, Koeppe RA, Minoshima S: Limbic activation and psychophysiologic responses to aversive visual stimuli. Interaction with cognitive task. Neuropsychopharmacology 2000, 23:508-516.

218. Liberzon I, Zubieta JK, Fig LM, Phan KL, Koeppe RA, Taylor SF: mu-Opioid receptors and limbic responses to aversive emotional stimuli. Proc Natl Acad Sci U S A 2002, 99:7084-7089.

219. Maddock RJ, Garrett AS, Buonocore MH: Posterior cingulate cortex activation by emotional words: $\mathrm{fMRI}$ evidence from a valence decision task. Hum Brain Mapp 2003, 18:30-41.

220. Meseguer V, Romero MJ, Barros-Loscertales A, Belloch V, Bosch-Morell F, Romero J, Avila C: Mapping the apetitive and aversive systems with emotional pictures using a block-design fMRI procedure. Psicothema 2007, 19:483-488.

221. Mirz F, Gjedde A, Sodkilde-Jrgensen H, Pedersen CB: Functional brain imaging of tinnitus-like perception induced by aversive auditory stimuli. Neuroreport 2000, 11:633-637.

222. Nitschke JB, Sarinopoulos I, Mackiewicz KL, Schaefer HS, Davidson RJ: Functional neuroanatomy of aversion and its anticipation. Neuroimage 2006, 29:106-116.

223. O'doherty JP, Deichmann R, Critchley HD, Dolan RJ: Neural responses during anticipation of a primary taste reward. Neuron 2002, 33:815-826.

224. Phan KL, Liberzon I, Welsh RC, Britton JC, Taylor SF: Habituation of rostral anterior cingulate cortex to repeated emotionally salient pictures. Neuropsychopharmacology 2003, 28:1344-1350.

225. Rolls ET: Functions of the orbitofrontal and pregenual cingulate cortex in taste, olfaction, appetite and emotion. Acta Physiol Hung 2008, 95:131-164.

226. Shirao N, Okamoto Y, Mantani T, Yamawaki S: Gender differences in brain activity generated by unpleasant word stimuli concerning body image: an fMRI study. Br J Psychiatry 2005, 186:48-53.

227. Tabbert K, Stark R, Kirsch P, Vaitl D: Hemodynamic responses of the amygdala, the orbitofrontal cortex and the visual cortex during a fear conditioning paradigm. Int J Psychophysiol 2005, 57:15-23.

228. Taylor SF, Liberzon I, Koeppe RA: The effect of graded aversive stimuli on limbic and visual activation. Neuropsychologia 2000, 38:1415-1425.

229. Taylor SF, Phan KL, Decker LR, Liberzon I: Subjective rating of emotionally salient stimuli modulates neural activity. Neuroimage 2003, 18:650-659.

230. Zald DH, Pardo JV: The neural correlates of aversive auditory stimulation. Neuroimage 2002, 16:746-753.

doi:10.1186/1471-2202-13-60

Cite this article as: Hayes and Northoff: Common brain activations for painful and non-painful aversive stimuli. BMC Neuroscience 2012 13:60.

\section{Submit your next manuscript to BioMed Central and take full advantage of:}

- Convenient online submission

- Thorough peer review

- No space constraints or color figure charges

- Immediate publication on acceptance

- Inclusion in PubMed, CAS, Scopus and Google Scholar

- Research which is freely available for redistribution

Submit your manuscript at www.biomedcentral.com/submit 